


\section{Helminthologische}

\section{Studien und Beobachtungen.}

Von

\section{Dr. med. Friedrich Mosler,}

a. 0. Professor in Giessen.

Mit zwei farbigen Tafeln.

Berlin, 1864.

Verlag von August Hirschwald,

Luter den Linden No. ES. 


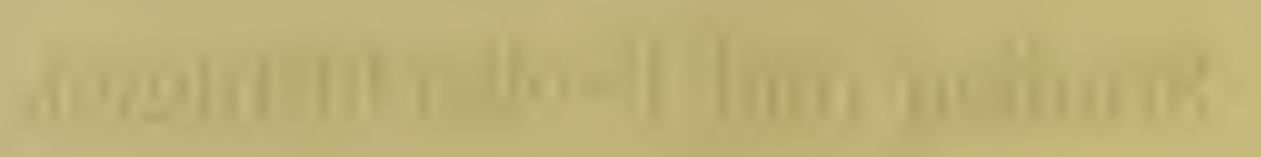




\author{
Den Herren
}

\title{
Rudolf Leuckart,
}

Professor der Zoologie und vergleichenden Anatomie in Giessen,

und

\section{Eugen Seitz,}

Professor der Pathologie und Therapie in Giessen,

hochachtungsvoll

gewidmet. 
Helve I I Hown 


\section{Vor w or t.}

Das helminthologische Studium gewinnt täglich allgemeineres Interesse, je mehr uns die glänzenden Entdeckungen der experimentirenden Parasitenlehre über die weite Verbreitung und die wichtige Rolle der Parasiten aufklären. Der physiologischen Medicin ist durch das helminthologische Experiment eine neue Bahn geöffnet, die Entstelıng und das Wesen von lirankheiten zu studiren, die vordem unerklärt waren; eine gründliche Prüfung der anthelminthischen Heilmittel ist allein auf diesem Wege möglich. Indem ich durch Herrn Professor Leuckart, den eben so unermüdlichen, als glücklichen Forscher auf dem Gebiete der Helminthologie, vielfach Anregung zu eigenen Untersuchungen erhielt, habe ich mit Benutzung seines trefflichen Institutes eine Reihe helminthologischer Experimente begonnen, welche, obgleich sie noch nicht abgeschlossen sind, doch schon einige für Diagnose und Therapie der Helminthiasis wich- 
tige Resultate geliefert haben. Wenn es mir dureh die Verhältnisse gestattet sein wird, diese Studien fortzusetzen, beabsichtige ich mit der Zoit eine Klinik ler durch thierische Parasiten bedingten Krankheiten des Menschen herauszugeben. Für dicses Unternehnen hahe ich durch Herrn Professor Seitz zahlreiche Aufmunterung und Unterstützung erhalten. Ich freue mich, diesen beiden Collegen und Freunden durch Widmung dieser Blätter meine aufrichtige Verehrung bezeugen zu können.

Berlin, im November 1863. 


\section{I th ha a t.}

Seite

1. Ueber akute Cestoden-Tuberculose............. I

11. Negatives Rrsultat der Fütterung mit Taenia solium beim Rinde....................... . . . 23

11I. Negatives Resultat der Fütterung mit Muskeltrichinen beim Rinde...................... 25

IV. Ueber die Pikrinsäure und ihre Bedeutung als Anthelminthicum 29

V. Ueber das Benzin und seine anthelminthische Wirkung .. . 57 

I.

\title{
Veher aknte Cestoden - 'T'uberculose,
}

\author{
ein Beitrag zur Finnenkrankheit.
}

(Hierzu Tafel 1. u. 2.)

$\mathrm{V}$ worden, dass die weissen Knötchen, welche die Jugendzustände verschiedener Finnen darstellen, mit den gewöhnlichen Tuberkeln der Lunge, der Leber und anderer Organe eine auffallende Aehnlichkeit haben und mit blossem Auge von ihnen nicht unterschieden werden können. Es erwähnt Leuckart*) dieser Befunde in folgender Weise:

"Die Leber war in ähnlicher Weise, wie das bei len Fütterungsversuchen mit Taenia crassicollis beschrieben worden, mit kleinen zun Theil noch punktförmig weissen Knötchen durchsïet, nur die Zall dieser Gebilde hier unendlich viel grösser war und auf viele tausende veranschlagt werden konnte. Das Aussehen der Leber war - wie auch llaubner und Küchenmeister in einem ähnlichen Falle hervorheben - genan dasselbe, wie bei einer

*) Ueber die liasenbandwürmel und deren Lintwicklung. Giessen 1856, p. 43. 
Miliartuberkulose, so dass man ohne Kenntniss des eingeleiteten Experimentes dieselbe ganz bestimmt auch in diesem Sinne dingnosticirt haben würde. Die grössesten der betreffenden Knötchen maassen etwa 1 Mm., doch war die Mehrzahl bedentend kleiner. Ich habe das Vergnügen gehabt, zu verschiedenen Malen solche Lebern meinen hiesigen Collegen, namentlich den Professoren J. Vogel, Wernher und Bisch off vorzulegen, und kann mich auch bei obigem Ausspruche auf die Autorität dieser Männer berufen. Wer weiss, wie oftmals schon die massenhafte Einwanderung von Parasitenkeimen, die auch bei den Thieren keineswegs ohne mancherlei krankhafte, vorzugsweise febrile Erscheinungen vor sich geht, für eine Miliartuberkulose gehalten worden ist."

Durch meine neuesten Fütterungsexperimente, welche ich mit Taenia mediocanellata beim Rinde vornahm, habe ich mich überzeugt, dass die oben erwähnte Verwechslung seh" leicht statthaben kann, indem nicht allein der Sectionsbefund, sondern auch das Krankheitsbild im Leben grosse Uebereinstimmung mit der akuten Miliartuberkulose darbot. Der Wiclitigkeit des Gegenstandes wegen erachte ich es darum für praktisch, auch in der Bezeichnung dieses Krankheitszustandes an die so leicht gegebene Verwechslung beider Geschwulstformen zu erinnern, und möchte darum der von Leuckart mir vorgeschlagene Name der akuten Cestoden-Tuberculose am Platze sein.

Ausserdem hat die folgende Mittheilung für klinische Zwecke dadurch noch ein ganz besonderes Interesse, dass sie weitere Beiträge liefert für das Zustandekommen einer akuten Helminthiasis und neue Beweise giebt für die Artberechtigung von Taenia solium und Taenia mediocanellata. Indem ich vielfach erfahren have, 
dass diese für die praktischen Zwecke in mehrfacher Hinsicht höchst wichtige Unterscheidung von den Aerzten noch nicht hinreichend gewürdigt wird, werde ich der Mittheilung: meiner Fütterungsexperimente Einiges über die Unterschiede von Taenia solium und Taenia mediocanellata vorausschicken.

Dass die beim Menschen vorkommenden Bandwürmer mancherlei Verschiedenheiten in Form und Aussehen darbieten, war schon lange bekannt. Selbst der bekannte Pastor Goetze hatte zwei Spielarten unterschieden, eine Taenia cucurbitina plana, pellucida, und eine Taenia cucurbitina grandis, saginata, die im Ganzen mit unserer heutigen Taenia solium und Taenia mediocanellata übereinstimmen dürften, obwohl Goetze auch letzterer eine Kopfbewaffnung zuspricht. Dass es überhaupt auch unbewaffnete Menschenbandwürmer giebt, ist zuerst von Bremser beobachtet worden. Er behauptet nämlich, bei den von ihm in Wien beobachteten Exemplaren niemals einen Hakenkranz gesehen zu haben, obwohl ein von Rudolphi aus Berlin ihm übersandter Kopl einen solchen aufs deutlichste zeigte. Die zur Ausgleichung dieser Verschiedenheiten von Bremser aufgestellte Vermuthung, dass die Taenia solium mit zunehmendem Alter nicht selten ihren Hakenkranz verliere, ist seitden oftmals von Aerzten ausgesprochen worden; allmälig hat man sich indess überzeugt, dass beide Formen eine unverkenubare Bezielıng zu gewissen Lokalverhältuissen besitzen. Wie Bremser, so salı nämlich anch Wawruch in Wien unter den sehr zahlreichen von ihm abgetriebenen Tänien nie ein bewaffinetes Individuum. Ebenso findet sich nach We ishaar's umfassenden Erfahrungen in dem südöstlichen Würtemberg und den angrenzenden Theilen Bayerns fast ausschliesslich die unbewaffnete Tänie, 
während in den von Neckar durchströmten nörulichen Gegenden Würtembergs (nach Seeger) fast eben so ausschliesslich, wie im nördlichen Deutschland, die bewaffiete Form vorkomut. In unseren Gegenden, in westlichen Theile von Mitteldeutschland, kommen beide Folmen ueben einander vor, nach meinen Erfahrungen indess die Taenia solium häutiger, als die Taenia mediocanellata, indem von 57 Bandwürmern, die ich bis dahin abgetrieben, nur 12 der Taenia mediocanellata und 45 der Taenia solium zuzurechnen waren.

Obwohl noch von vielen anderen Acrzten, selbst ausserhalb Europa's, derartige Beobachtungen gemacht wurden, welche auf ein solches theilweise an gewisse lokale Verlıältnisse gebundenes Vorkommen der genannten beideı Arten des gewöhnlichen Bandwurmes aufmerlisam machten, drang die so wichtige Differenzirung derselben doch nicht

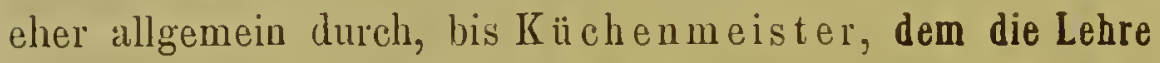
von den Cestoden so unendlich Vieles zu verdanken hat, weiter noch hervorhob, dass die unbewaffnete Form des Menschenbandwurmes niclit blos durcli Abwesenheit des Hakenkranzes, sondern zugleich durch Mangel des Rostellums, das doch schwerlich ausfallen könne, und dureh beträchtlichere Grösse der Saugnäpfe von der bewaffneten Taenia solium verschieden sei, anch überdies ein feisteres Ausselıen besitze, und eine viel reichere Uterinver'zweigung erkemen lasse. Unter solchen Unständen müsse dieselbe als eine besondere Species betrachtet werden, die vielleicht nicht ganz unpassend den Namen Taenia mediocanellata trage.

Seitdem haben uns R. Leukal't's aluggezeichned. gründliclı e Forschungen, wie sie in semer Naturgeschichte der thierischen Parasiten 1. p. 288 11. f. mitgetlieilt 
sind, noch viel weiter gebracht in der Kenntniss der Unterschiede beider Bandwurmarten, und ist es dadureh jedem Arzte möglich gemacht, im speciellen Falle zwischen Taenia solium und mediocanellata zu unterscheiden, wenn er als besonders charakteristisch auf die Bildung des Kopfes, die Grösse und das feiste Aussclen der Proglottiden und auf den Bau des Uterus aclitct. $\mathrm{Ob}$ diese drei Charaktere stets mit cinander combinirt scicn, ist durch die bisherigen Beobachtungen noch nicht genügend festgestellt. Nach meinen Erfalırungen scheinen sie nicht immer zusammen zu treffen. So habe ich noch am 24. Juni d. J. die Proglottiden eines von einer Patientin abgegangenen Bandwurmes ihres feisten Ausseliens und der reichen Uterinverzweigung wegen der Taenia mediocanellata zugelıörig erachtet, bis mich bei ciner späteren Kur die Anwesenlieit der Iakenkränze der beiden nunmchr abgegangenen Köpte vom Gegenthcile ïberzcugten. Auch Lenckart ist der Ansicht, dass man in Betreff des Aussehens und der Kettenform bei beiderlei Arten von Tänien eine gewisse Breite der Variabilität zugeben müsse, da auf das Aussehen und die Natur mancherlei äussere Momente cinwirken könnten. Unter den oben genannten Hauptkennzeichen muss daher der Kopfbild ung die erste, und der Uterusform die zweite Stelle gegeben werden.

Wer jemals einen Kopf der Taenia mediocanellata grïndlich untersucht liat, wird nicht mehr zweifeln an der Richtigkeit der von Küchenmeister und Leuckart dafür angegebenen Charaktere.

Schon bei oberflärhlicher Vergleichung desselben mit Taenia solium fällt die beträchtlichere Grösse und die mehr eckige Form auf. Beides hängt davon ab, dass die Saugnäpfe der Taenia merlincanellata eine sehr viel 
stärkere Fntwicklung besitzen, als das hei dem bewaffneten Bandwurm der Fall ist. Dass diese Bildung der Saugnäpfe einen Ersatz für den mangelnden Hakenapparat bietet, davon hat sich wohl schon jeder Arzt ïberzeugt, der sich mit Bandwurmkuren abgegeben; es ist dadurch die vollständige Abtreibung der Taenia mediocanellata um vieles schwieriger, erfordert ganz besondere Unterstützungsmittel der Kur. Dass dem Wurme der Hakenapparat wirklich fehlt, lässt sich schon aus der Form des Kopfes erschliessen. Der Scheitel ist flach, und mitunter sogar vertieft, so dass die Ränder der Saugnäpfe ïber denselben hervorspringen. Zur Gewissheit wird diese Abwesenheit erst bei näherer Untersuchung. Drïckt man den Kopf zwischen zwei Glasplatten, so erblickt man schon mit unbewaffinetem Ange die vier, meist von schwarzem Pigmente umgebenen Saugnäpfe, aber beständig ohne das bei Taenia solium dazwischen gelegene Rostellum mit dem Haken. Auch bei stärkerer Vergrösserung lässt sich keine Spur dieser Gebilde nachweisen. Dass dies nicht als zufälliges Vorkommen anzusehen ist, geht mit Bestimmtheit daraus hervor, dass Leuckart bei vielen Köpfen, welche er zu untersuchen Gelegenheit hatte, eine durchaus übereinstimmende Bildung vorfand, überall dieselbe beträchtliche Grösse, dieselbe kräftige Entwicklung der Saugnäpfe, dieselbe Abwesenheit der Haken nicht blos, sondern auch des Rostellums, das bei Taenia solium selbst nach Verlust des Hakenkranzes noch beständig nachweisbar bleibt.

Nicht ganz so constant, wiewohl auffallend, ist der Unterschied der Uterinbildung in Betreff der viel reichlicheren und dichter gedrängten Seitenäste. Meist macht sich diese Eigenthümlichkeit schon bei Beginn der Uterinverzweigung geltend, indem die Seitenäste gleich von Anfang an in ihrer 
ganzen Menge hervorgetrieben werden; es beschränken sich dann die späteren Veränderungen auf ein Auswachsen und die Entwicklung dichotomischer Spaltungen, die sich in Verlaufe der Seitenzweige meist mehrfach wiederholen, so dass die Zahl der Ausläuler schliesslich bis $\delta 0$ und darüber jederseits erhöht wird. In allen Exemplaren von Taenia mediocanellata, welche ich bis dahin untersuchen konnte, labe ich diese Eigenthümlichkeit der Uterinbildung angetroffen. Es sind mir aber Proglottiden von Taenia solium vorgekommen, in denen diẹ Seitenzweige des Uterus durch eine grössere Zahl von der Norm abwichen, und welche auch noch durch grössere Feistigkeit, durch bedeutendere Breite den Gliedern der Taenia medjocanellata so nahe kamen, dass ich in 2 bis 3 Fällen über die wahre Natur der von mir untersuchten Präparate so lange in Zweifel gewesen bin, bis ich bei wiederholter Kur durch Abtreibung des Kopfes Gewissheit erlangte.

Die Artberechtigung der Trenia mediocanellata wurde mir hiernach nicht zweifelhaft. Doch hatte es ein besonderes Interesse für mich, auf dem Wege des Experimentes einige gründliche Nachforschungen anzustellen, mir durch eigene Anschaung über einzelne wichtige Punkte dieser Frage Gewissheit zu verschaffen. Zunächst wollte ich die näheren Eigenthümlichkeiten der durch Fïtterung erzogenen Jugendform der Taenia mediocanellata beim Rinde und die dadurcli veranlassten Krankheitserscheinungen studiren; weiterhin liam es mir darauf an, Mittel zu versuchen, welche die weitere Entwicklung der Fiunen beim Rinde aufhalten möchtẹn. Es sind dies die Gründe, welche mich veranlassten, den von Leuckart bereits eingeschlagenen Tieg der Fütterung von Taenia mediocanellata an ein Rind wieder 
aufzunehmen. Es bot sich mir dazu Crolegenleit an 3. März 1863, als ich einem 26 Jahre alten Mälchen mit 2 Draclimen des Fxtractum Filicis aetloreum etwa 4 Jillen reifer Proglottiden von Taenia mediocanellata abgetrieben, wovon ich für's Erste 100 reife Proglottiden am 10. Mär\% Nachmittags 3 Ulır, nachdem die Tänie sicben Tage in Wasser aufbewahrt worder war, einem gesunden, kräftig entwickelten, etwa $2 \frac{1}{2}$ Monate alten Kalbe mit Milch in den Rachen einschüttete. Unmittelbar darnach wurde das Thier noclı länger beobachtet, $11 \mathrm{~m}$ zu erfahren, ob die Proglottiden anch wirklich bei ihm blieben. Die folgenden Tage zcigte dasselbe in keiner Weise eine Veränderung.

Am 13. März wurde nocll eine weitere Fütterung mit 50 Proglottiden derselben Tänie vorgenommen, wo n ach das Thier im Ganzen $\mathbf{1 5 0}$ Proglottiden erlialten. Fis blieb munter und ansclieinend gesund, bis sich am 21. Mär $1 \%$, also 11 Tage nach der ersten, und 8 Tage nach del zweiten Füttermng mancherlei krankhafte Erscheimungen einstellten. Es hatte ein verändertes Aussehen, war traurig, konnte sich nur mülısam aufrichten, sank im Gehen mitunter auf die Kniee, frass wenig, hatte aufgetriebenen Bauch, ganz dïnne Entleerungen. Eigenthümlich war noch Zittern der Beine und schaukelnde Bewegungen des Kopfes von einer Seite zur anderen, wozu sich Fiebererregung gesellte. Mit Gewissheit glaubte ich annehmen zu dürfen, dass diese Krankheitserscheinungen durch die gefütterten Helminthen zu Stande gekommen, das Leiden demnach als solı akute Helmintliasis anzusehen sei, besonders da sonst keine Veranlassung fiir derartige Symptome vorlag, überdies 150 Proglottiden nach frïheren Erfahrungen von Leuckart eine zum Fütterungsexperiment mit Tacuia mediocanellata sehr loohe 
Zahl ist, die ich nur in Rücksicht der kräftigen Constitution des Thieres anznwenden wagte. Bei dem einen Kalbe, das $L$, uckart zu seinem Fïtterungsex periment benutzt, wurden Anfangs 25 Stück und später in Zwischenräumen von 5 oder 6 Tagen noch einige Male 5-8 Stïck beigebracht, wobei Im Ganzen zwischen 40 und 50 Glieder verfiittert worden waren. Selbst nach dieser verhältnissmässig geringen Portion von Proglottiden (nur $\frac{1}{3}$ der in unserem Falle verfïtterten) hatten sich gleichfalls etwa ?0 Tage nach der ersten Infektion mancherlei krankhafte Erscheinungen, Appetitlosigkeit, Mattigkeit, Sträuben des Haares, Fiebererregung eingestellt, die sich allmälig zu einem solchen Grade steigerten, dass eine Zeit lang für das Leben des Thieres gefürchtet werden musste. Erst gegen Ende der zweiten Woche liess die Krankheit nach, bis schliesslich wiecier vollständige Genesung von selbst eintrat.

In unserem Falle waren die Krankheitserscheinungen insgesammt viel ausgeprägter, entsprechend der grösseren Menge der gefütterten Proglottiden und dadurch anch reichlicher stattgehabten Fintwicklung von Finnen. Es war darum weniger Aussicht auf spontane Genesung vorhanden, und die Gelegenheit um so günstiger, eine antihelminthische Kurmethode zu versuclien.

Am 21. März zwischen 4 und 5 Ulır brachte ich deshalb 5 Gran Kali picro-nitricum, die zusammen in eine Pille verarbeitet wiren, vorsichtig tief in den Rachen des Thieres ein, und liess es einige Zeit ausserhalb des Stalles herumführen, um zu controliren, ob die Pille nicht alsbald durch Wiederkäuen ausgegeben werde. Das Mittel wurde anscheinend gut vertragen. Am 22.2. März war das Thier munterer, frass etwas mehr, der stark anfgetriebene Bauch war beigefallen, die Ausleerungen waren minder häufig. Im 
Latufe dieses Tages wurden noch 3 Mal 5 Gran Kali picronitr. in der oben geschilderten Weise eingegeben.

Am 23. Mär\% war das Befinden des Thieres anscheinend noch besser, und wurde wiederum eine Pille von 5 Gran Kali picro-nitric. gegeben.

Am 26. März war das Thier wieder atulfallend matt und traurig. Der Bauch eingefatlen; Magerkeit hatte zugenommen. Es wurden 2 Mal 5 Gran Kali picro-nitric. gegeben.

Am 27. März derselbe Zustand. Wiederholung derselben Gabe des Mittels.

Am 29. März einige Besserung; munteres Aussehen. 10 Gran Kali picro-nitric.

Am 30. März wal das Thier so unwohl und schwach, dass es nur sehr schwer stehen lionnte; struppiges Haar, reichliche Schweisse, profuse Diarrhöen, abdominelle Respiration; nach Angabe von Herrn Kroug, eines hier studirenden Landwirthes ans St. Petersburg, der die Krankheit mit beobachtete, hatte das Thier auch Brechneigung. Appetitmangel war nunmehr vollständig. Am Nachmittag war eine solche Lähmung der Extremitäten hinzugekommen, dass es ausser Stande war, nocli aufzustelien, und gerade so liegen blieb, wie man es gelagert hatte. Es wurden noch 10 Gran Kali picro-nitric. gegeben. Alle anwesenden Viehzüchter und Landwirthe, denen iclı das Thier vorzeigte, verzweifelten an seinem Aufliommen. Abends 7 Uhr fand ich dasselbe, als ich es noch einmal mit Herrn Professor Lenckart und Herrn Dr. Mettenlieimer besuchte, wieder stehend und etwas fressend; es war aber sehr abgemagert, zitterte sehr mit den Beinen, bowegte den Kopf schaukelnd von einer Seite zur andern; der Bauch war stark eingefallen, die Abgängre dünn. 
Es wurden nochmals 5 Gran Kali picro-nitricum gegeben.

Am 31. März Morgens zeigte sich eine vorübergehende Besserung, am Abend war das Thier aber kränker, als je zuvor; es erhielt 10 Gran Kali picro-nitric.

Am 1. April lag es vollständig apathisch anf dem Rücken, liatte Zuckungen am ganzen Körper, besonders anch des Koples; erhielt noch eine Pille.

Um 9 Uhr Morgens erfolgte der Tod unter Convulsionen. Mittags 2 Uhr, also 5 Stunden nach dem Tode, liabe ich auf dem liesigen zoologischen Iustitute in Gegenwart von Herrn Professor Leuckart und Herrn Hofrath Müller Il. aus Homburg die Seetion vorgenommen und folgende Befunde erhalten:

Das Thier ziemlich abgemagert; mässige Todtenstarre. Bauch stark aufgetrieben. Thorax etwas eingefallen. Unterhautzellgewebe an vielen Stellen, besonders am Halse in der Gegend der Glandula thymus, in der Achselhöhle, der Leistengegend, überhaupt da, wo reichlich Lymphdrüsen vorhanden, stark serös infiltrirt, sulzig. Die Muskeln von intensiv rother Farbe, ihre Gefässe überfüllt, an vielen Stellen längs des Verlaufes der Muskelfasern streilige Extravasate. Die Muskelsubstánz succulent, an einzelnen Stellen erweicht. Sämmtliche von mir untersuchte Muskeln waren mit zahlreichen Finnen durchsetzt, zumeist das Zwerchfell, die Muskeln der Brust, der Schultern und des Nackens; anch in der Muskulatur der Extremitäten waren sie zahlreich. Im Zwerchfell waren einzelne Cysten streifenartig lang gezogen, wahrscheinlich dadurch entstanden, dass die Embryonen selbst in der Kapsel noch ihre Wanderung fortgesetzt, deren Wandung vor sich hergedrängt und lang gezogen batten. 
Auch zwischen den einzelnen Mnskeln fand sich stellenweise das Zellgewebe stark serös infiltrirt, an manchen Stellen von etwas gelblicher Farbe, doch war der Farbstoff nicht so intensiv, dass ich ilın von der Pikrinsäure lrerrïlıend annehmen möchte, wie siclı ïberliaupt nirgends im ganzen Körper entscliedene Spuren derselben zeigten. Bei Eröffnung der Schädlelhöhle fiel der Blutreichthum der grösseren und kleineren Venen anf, besonders zeigten sich die Hirnhäute stark hyperämisch, zumal an der Hirnbasis, wo sich hinter der Pons Varolii ein blutig seröser Erguss fand; an anderen Stellen der Pia mater kleinere Extravasate. Die Hirnsubstanz selbst feucht, etwas weich; die Seitenventrikel ausgedelınt durch seröse Flüssigkeit. Beim Durclıschneiden der Hirnsubstanz einzelne stecknadelkopfgrosse Extravasate. Weder anf der Oberfläche des Geliirns, noch im Innern fanden sich Finnen.

Der Herzbentel, stark ausgedehnt, mässig blutreich, hatte nur wenige Finnen in der hinteren unteren Partie. Das Herz selbst zeigte, wie die beigegebenen Tafeln deutlich darthun, die auffallendsten Befunde; vor Allem war es sehr stark vergrössert, nach Aussage des Herrn Möhl, den ich zur näheren Erklärung einiger Befunde zugezogen, mehr als um $\frac{1}{6}$ vergrössert. Der Umfang an der Basis war = $27 \mathrm{Cm}$; der vertikale Durchmesser von der Helzbasis am Ursprung der grossen Gefässe bis zur Herzspitze $=13 \mathrm{Cm}$. Die Oberfläche des Herzens stark glänzend, von intensiv rother Farbe, mit zahlreichen, länglich ovalen, stecknadelkopf- bis linsengrossen Knötchen besetzt, welche die auffallendste Aehnlichkeit mit den gewöhnlichen T'uberkeln haben. An vielen Stellen 
sassen sie reihenweise längs des Verlaufes der Muskelfaser"n sowohl an der hinteren, als vorderen Fläche, melır am rechten, als linken Ventrikel, viel weniger an beiden Vorhöfen. Beim Einschneiden der Wandungen fiel die sehr beträchtliche Dicke beider Ventrikel auf, am linken $=3 \mathrm{Cm}$, am rechten $=2 \mathrm{Cm}$. Durcli die ganze Dicke wal die Muskelsubstanz von unzälligen solcher Knötchen durchsetzt. Einzelne leuchteten durch das Endocardium durch, hatten dasselbe an manchen Stellen emporgehoben; davon waren mehr im rechten, als linken Ventrikel zu sehen. Das Endocardium selbst zeigte keine Veränderung, es war blass, die Klappen normal, zart, ohne Knütchen; desgleichen die Klappen der Aorta und Pulmonalis, sowie die Wandungen sämmtlicher Gefässe, die untersucht wurden. In beiden Herzhöhlen sehr wenig Coagula, dagegen die grösseren Venen stark ïberfüllt. Im Brustfellraume beiderseits $\frac{1}{2}$ Schoppen gelblich seröser Flüssigkeit, das Brustfell normal glatt, glänzend, einzelne Küötchen zeigend, wolche von circumscripten Extravasaten umgeben waren. Linke Lunge durch das stark ausgedehnte Her' etwas nach rückwärts geschoben, mässig comprimirt, blutreich, sank in Wasser nicht ganz unter. Rechte Lunge ebenfalls blutreich, sonst normal. Die Schleimhaut des Larynx, der Trachea, der Bronchien bot nichts Abnormes. Sämmtliclie Respirationsorgane frei von Finnen.

Die Zunge zeigte an ihrer unteren freien Flüche etwa 15-18 weiss durchscheinende Knötchen; beim Einschneiden in die Zungensubstanz präsentirte sich eine massenhafte Ablagerung von Finnen, auch in der Muskelschicht des Schlundkopfes und Oesoplıagus eine mässige Anzahl, zahlreicher in dem sie unlagernden Zellgewebe; selbst in der Muskulatur des Darmkanales waren einzelne solcher Knöt- 
chen anfzufinden. Es zeigte im Uebrigen der Darm an seinen sämmtlichen Häuten aufallende Hyperänie; der Inlialt ans dïınen, hellen Fäkalmassen bestehend, die Schleimhaut mit einer dicken Schleimschicht bedeckt, darunter stark erweiterte Gefässe, an manchen Stellen linsen- bis erbsengrosse Extravasate; sümmtliche Schleimhautdrüsen stark geschwellt. Die Gefässe des Peritonemms und Mesenteriums gleichfalls stark entwickelt, an einzelnen Stellen auch hier kleinere Extravasate. Die Lymphgefässe auffallend erweitert, und dadurch deutlich sichtbar in ihrem Verlaufe zum Darme. Die Lymphdrüsen im hinteren Bauch- und Brustraume grossentheils angeschwollen bis zu Erbsen- und Nussgrösse, von hellröthlichem, manche von dunkelrothem Aussehen durch darin stattgehabte Blutextravasation. Im Peritonealcavum etwa $1-1 \frac{1}{2}$ Schoppen hellseröser Flüssigkeit. Die hinteren Partieen des Peritoneums gegen die Wirbelsäule zu waren am meisten geröthet, das subseröse Zellgewebe stark serös infiltrirt, sulzig, ron gelblicher Farbe; zahlreiche Finnen waren daselbst eingebettet; besonders fanden sich dieselben in der sehr aufgelockerten blutreichen Nierenkapsel. Die Nieren selbst waren nach einer Schätzung des Herrn Möhl um das Dreifache ihres normalen Volumens vergrössert, sehr blutreich; in ilrrer Substanz selbst keine Knötchen, dagegen in mässiger Zahl in dem das Nierenbecken auskleidenden Zellgewebe. Harnleiter und Harnblase normal.

Leber vergrössert, blutreich, enthielt keine Finnen; an der concaven Fläche zahlreiche, stark amgeschwellte Lymphdrüsen. Milz normal.

Die Genitalorgane zeigten keine Veränderung.

Was schliesslich die genauere Untersuchung der massenhaft in Körper vorgefundenen Knötchen anlangt, so 
enthielt jedes zum Unterschiede von den gewöhnlichen Tuberkeln einen wohl erhaltenen Cysticercus. Ihr äusseres Ansehen hatte allerdings so grosse Aehnlichkeit mit gewöhnlichen Tuberkeln, dass bei oberflächlicher Beobachtung eine Verwechslung hätte unterlaufen müssen; noch melı hielten sie alle Aerzte, denen ich später das in Spiritus aufbewahrte Herz vorzeigte, für gewöhnliche Tuberkelablagerung im Herzen und staunten wegen der frappanten Aehnlichkeit. Auch im frischen $\mathrm{Zu}-$ stande hatten die meist $1-3 \mathrm{Mm}$. breiten und 2-4 Mm. langen Knötchen ein weissliches Aussehen, als wenn sie mit Tuberkel-Masse erfüllt wären; beim Einschneiden der festen Bindegewebshälle entleerte sich ein zelliger Inhalt, in welchem das etwa $0,5-1,5$ Mm. im Durchmesser lialtende Cysticercusbläschen aufzufinden war. Das Innere desselben verhielt sich ganz so, wie es von Leuckart pag. 294 seines schon erwähnten Werkes beschrieben ist. Gefässe konnten darin noch nicht aufgefunden werden, dagegen zeigten manche bereits die ersten Anfänge des Kopfzapfens.

Durch diesen Versuch in Verbindung mit dem unten erwähuten negativen Resultate der Fütterung von Taenia solium bei einem anderen Rinde ist die specifische $\mathrm{Na}$ tur der Taenia mediocanellata anfs Neue bewiesen, und weiterhiu, dass ilur Cysticercus nicht blos die Muskeln, sondern noch zahlreiche innere Organe des Rindes bewolnt in einer Menge, wie wir sie nach Fïterung der 4 fachen Zahl von Proglottiden der Taenia solium beim Schweine niemals gesehen haben. Der Zahl nach kommen dieselben am meisten vor in dem $\mathrm{Z}$ werelıfell, in den Muskeln der Brust, der Schultern und des Nackens; von 
inneren Organen war an meisten davon durchsetat das Herz, welches in Folge der darlurch bedingten Reizung stark hypertrophisch geworden war; darnach kaın die Zunge, während in den muskulösen Wandungen des Oesophagus und des Darmes nur wenige Finnen abgelagert waren. Mehr fanden sich dieselben in Peritoneum, besonders in der hinteren Partie der Wirbelsäule zu. Die Nierensubstanz selbst war frei davon; einzelne waren zerstreut in den Nierenbecken; ganz frei davon waren Leber und Milz, die sämmtlichen Respirationsorgane, die Genitalorgane, das Gehirn und Rückemmark. In Leuckart's Falle fand sich auch in Geline etwal ein Dutzend Bläsclen, meist frei zwischen den Windungen der Hemisphären. Doch war der Zustand des Gelirnes nicht der Art, dass davon die Todesursache abhängig gemachit werden konnte. Vielmehr ist Leuckart der Ansicht, diss in seinem Falle die Todesursache in dem ausgebreiteten Leiden des Lympligefässsystems zu suchen und dieses selbst auf den von den eingewanderten und in Masse sich entwickelnden Parasiten ausgehenden Reizzustand zurückzuführen sei. Auch in meinem Falle war das Leiden des Lymphgefässsystems stark ausgesprochen, so dass es immerhin als ein der akuten Finnenkrankheit constant zukommendes Zeichen angeselien werden darf, welches die Verwechselung mit der gewöhnlichen akuten Tuberkulose begüustigt. Das Eintreten des Todes dürfte dagegen in unserem Falle anders zu erkiären seiu.

Zielıen wir die Erscheinungen im Leben in Betracht, so wïrde Niemand, selbst der erfahrenste Thierarzt nicht, im Stande gewesen sein, hieraus das wirkliche Leiden zu diagnosticiren. Da sich die Bedingungen einer so missenlisfen Einwanderung von Helminthenkeinen wohl nur sel- 
ten oder gar nieht bei dem natürliehen Verkehre der Thiere ohne Weiteres zusammenfinden, ist das Bild einer Finnenkrankheit gewöhnlich ein ganz anderes, nicht allein dass es keine akuten fieberhaften Symptome mit sich führt, es ist das Uebel meist ein allmälig entstehendes. mit wenig Ausnahmen schmerzloses, und die Funktionen in keiner Weise störendes. Das dureh Fiitterung mit Taenia medioeanellata künstlich geschaffene Krankheitsbild ist hiervon sehr verschieden, und hat dadureh noeh ein ganz besonderes Interesse, lass es, mit Rücksicht auf meine vergleichenden Versuche mit Titenia solium hei Schweinen, dic viel grössere Gefährliehkeit der Infektion mit Trania medioeanellata in Folge der massenhafteren Finnenproduktion der einzelnen Proglottiden beweist. Wir müssen es darum als ein Glück fïr den Mensehen ansehen, dass die Embryonen der Taenia merliocanellatir im menschlichen Organismus nicht für ilıre Entwicklıng günstige Verhältnisse vorfinden, der Menseh sich nicht, soweit die bisherigen Erfahrungen reiehen, mit zufällig in seinen Magen gelangenden Proglottiden derselben selbst infieiren kann.

Meine vergleichenden Versuehe bei 5 Sehweinen, die ich massenhaft, einige in verschiedenen Pausen zusammen mit 3 400 reifen Gliedern der Taenia solium gefüttert, haben nämlich folgendes Resultat ergeben: es traten eines Theilsitkeine merkharen Symptone auf, hatten sich überhaupt die Finnen nur in viel spärlicherer Menge, als naeh Fütterung des Rindes mit Taenia medioeanellata entwiekelt. Es gesteheñ auch die Thierarzte schon lange, dass die Diagnose der'Sehweine-Finnen aus deı sogenannten Finnenzeielen überhaupt eine prekäre Sache sei (Siche Relirs in Gurlt und Hértwigs Magazin für Thierheilkunde VIIJ 1842 p. 227) und foch war das Er- 
kennen der Fiunenkrankheit bei den Schweinen für den Landmann und den Schlächter schon lange, ehe man von dem Wesen dieser Cysten die richtige Anschauung liatte, von grosser Wichtigkeit.

Möglicher Weise wird in der Folge aus dem eben geschilderten Symptomencomplex das eine oder andere Symptom bei genauerer Beachtung fiir die Diagnose der Finnenkrankheit im Allgemeinen sich noch verwerthen lassen, und ist vielleicht der von uns gewählte Name lierfür nicht ohne Nutzen. Derselbe dürfte um so passender befunden werden, da obiges Krankheitsbild einige Aehnlichkeit hat mit den Erscheinungen der akuten Miliartuberkulose, welche ja auch unter dem Bilde eines typhösen Fiebers verläuft.

Bekanntlich wird der Verlauf derselben modificirt, und tritt noch schneller ein tödtlicher Ausgang ein, wenn sich tuberkulose Basilarmeningitis oder akuter Hydrocephalus hinzugesellt, welcher sich in unserem Falle durch das Eintreten zahlreicher Nervenerscheinungen anzeigte. Würden wir die kleinen Knötchen, welche die Finnen enthielten, auch in den Hirnhäuten gefunden haben, so würde uns die Veränderung im Gehirn auch ganz das Bild der tuberkulosen Basilarmeningitis geliefert haben.

Diese hydropische Ausschwitzung an der Hirnbasis und iı den Seitenventrikeln ist wohl ebenso, wie die an anderen Stellen vorgefundenen hydropischen Ausschwitzungen von der am Herzen vorgefundenen Veränderung abzuleitell. Es ist dieser Befund von massenlafter Finnenablagerung im Herzen um so bemerkenswerther, da bei einer anderen For'm der akuten Helminthiasis, nämlich der Trichiniasis, das Her'z bis jetzt ganz frei von Muskeltrichinen gefunden wurde. 
Dass das von uns angewandte Anthelminthicum, das Kah picronitricum hier ganz wirkungslos gewesen, unterliegt keinem Zweifel, da ja nicht einmal die Muskeln davon gefärbt waren.

Um die hier geschilderten Krankheitssymptome noch deutlicher ausgeprägt zu sehen, beabsichtigte ich anfangs durch Fütterung einer grösseren Zahl von Proglottiden, als im vorigen Versuche, ein noch exquisiteres Krankheitsbild zu schaffen. Leider war die Gelegenheit hierzu wegen des seltenen Vorkommens der Taenia mediocanellata in unserer Gegend nicht günstig. Indem ich mir keine grössere Zahl von Proglottiden verscliaffen konnte, musste ich mich mit der Fütterung von 100 Proglottiden begnügen. Sie wurde am 6. October 1863 bei einem 5 Monate alten Rinde vorgenommen. Unmittelbar darnach wurde das Thier genau beobachtet, damit es die Proglottiden wirklich bei sich behalte. Vom folgenden Tage an bis zum 24. Oktober wurden demselben $9 \frac{1}{2}$ Uncen Benzin in einzelnen Dosen, die bei einer anderen Gelegenheit ausführlich mitgetheilt werden sollen, eingegossen. Ausser Abmagerung und Schwäche der hinteren Extremitäten, Auftreibung des Bauches waren keine Krankheitserscheinungen wahrzunehmen. Besondere Umstände nöthigten mich, schon am 22. Tage nach der Fütterung den Versuch zu unterbrechen, und vergiftete ich desshalb am 28. Oktober das Thier mit Benzin. Bei der Section fanden sich in den Muskeln nur sparsame Finnen abgelagert, am meisten noch in den Bauch- und Brustmuskeln, sehr wenige in denen des Halses und der Extremitäten. Die meisten hatten im Vergleich zu deu im vorigen Versuch erwähnten ein verändertes Aussehen, waren gelblich, mehr als erbsengross, 
nit sehr derber Kapsel. Beim Einschneiden quoll eine gelbe, dickliche Masse heraus, die aus Fett und Bindegewebskörperchen bestand. In den meisten war der Cysticerkus untergegangen, etwa in dem Verhältniss, dass in 6 so aufgeschnittenen Cysten nur 1 Mal ein Cysticerkusbläschen aufgefunden wurde. Das Stadium der Entwicklung der Finnen war ganz dasselbe, wie in dem vorigen Falle. Finnen, die sich schon beim blossen Ansehen als wohlerhalten erwiesen, wie sie in dem vorigen Falle es insgesammt waren, fand ich in den Muskeln des Bauches sehr sparsam, etwas zahlreicher in dem Zwerchfell und dem Herzen; letzteres war wiederum stark vergrössert; an seiner Oberfläche, insbesondere auf dem linken Ventrikel, waren viele weisse Tuberkelchen von Hirsekornbis Linsengrösse, welche dem Herzen an einzelnen Stellen dasselbe Aussehen gaben, wie in dem vorigen Falle; daneben fanden sich erbsengrosse Knoten von mehr gelblichem Aussehen, deren Eigenthümlichkeit ich so eben beschrieben habe. Circumferenz des Herzens am Ursprung der Gefässe = 29 Ctm., vom Ursprung der Aorta bis zur Spitze des Herzens $=15 \mathrm{Ctm}$. Linker Ventrikel mit massigen, dunkelschwarzen Coagulis erfüllt. Wandung des linken Ventrikels $=3 \mathrm{Ctm}$. dick, die Muskelmasse roth, glänzend, von sehr zahlreichen weissen Knötchen, den Anfangsstadien der Finnen durchsetzt. Auf dem Endocardium ebenfalls zahlreiche Finnen bemerkbar, selbst auf dem grösseren Zipfel der Valvula bicuspidalis ') deutliche solcher Knötchen. Rechtes Herz von dunkelschwarzen Gerinnungen erfüllt; seine Wandungen $\frac{1}{2}$ Centimeter dick, gleichfalls nit zahlreichen Knötchen durchsetzt, welche zum Theil auf dem Endocardium hervorragten. In Mediastinum anticum, besonders in der oberen Partic ganze 
Stränge rosenkranzartig an einander gereihter, stark intumescirter Lymphdrüsen; in den hintern Partieen manche von Tauben- bis Hühnereigrösse, besonders unmittelbar unter dem arcus aortae; auf dem Durchschnitt die Substanz der Drüsen röthlich, mitunter körnig, meist weich. Lungen überall lufthaltig, in der rechten unmittelbar unter der Pleura wenige Finnen abgelagert, im Innern der Lungen fanden sich keine mehr. Beide Lungen sehr blutreich, die Bronchien mit schaumigem Sekrete, die Lungengefässe von dunkelschwarzen Coagulis erfüllt. In der Zunge waren dieses Mal nur wenige Finnen, im Oesophagus und Darm gar keine; auf dem Magen und dessen Schleimhaut Zeichen der Einwirkung des Benzines. Auch im Mesenterium waren gar keine Finnen abgelagert; seine Drüsen in bedeutendem Grade angeschwollen, solche von Tauben- und Hühnereigrösse lagerten dem Promontorium gegenüber; neben und auf der Aorta längs der Wirbelsäule rosenkranzartig neben einander gereihte, kleinere Lymphdrüsen, meist von dunkelrothem Aussehen durch darin stattgehabte Extravasation. Leber, Milz und Nieren zeigten nichts Auffallendes; auch das Gehirn und Rückenmark waren frei von solchen Knötchen.

In dem eben geschilderten Falle waren die Erscheinungen nicht so deutlich ausgesprochen, wie in dem ersten Falle, sowohl was die Erscheinungen im Leben, als den Sectionsbefund anlangt. Das im Alter schon weiter vorgeschrittene Thier vermochte den durch die Finnenund deren Wachsthum veranlassten Reizzustand besserzu ertragen und wardarumder Verlauf der Krankheit mehr latent; überdies war die Zahl der gefütterten Proglottiden eine geringere $(50$ 
weniger); ausserdem war dulch das in grossen Gaben angewandte Benzin wahrscheinlich ein Theil der Embryonen alsbald vernichtet, und das Absterben von einer nicht geringen Zahl der bereits in der En twicklung begriffenen Finnen herbeigefïhrt worden. 
II.

\section{Negatives Resultat der Fütterung von Taenia solium beim Rinde.}

Indem sich mir die Gelegenheit dazu bot, diesen di 8 Artenverschiedenheit von Taenia solium und mediocanellata noch mehr beweisenden Versuch zu wiederholen, habe ich dem letzteren der in der vorerwähnten Versuchsreihe genannten Rinder am 23. Juli 1863 25 reife Proglottiden, und am 24. Juli nochmals 30 solcher Proglottiden gefüttert. Dieselben hatten, was ihre Breite und weiterhin die Uterinverzweigungen anlangt, ganz den Charakter von Taenia mediocanellata, während sie die Köpfe mit Hakenkränzen — es waren bei der Kur 2 Köpfe abgegangen - der Taenia solium zugehörig erwiesen. Bei der am 29. October vorgenommenen Section konnte beim Durchsuchen des ganzen Rindes nicht eine einzige von dieser Fütterung stammende Finne aufgefunden werden. Die bei ihm gefundenen, schon oben erwähnten Finnen stammten sämmtlich von der 3 Wochen vor dem Tode stattgehabten Fütterung mit Taenia mediocanellata. Dass anch die theilweise degenerirten Finnen nicht auf die 
Fütterung mil Taenia solium zu bezichen waren, geht daraus hervor, dass sich in einzelnen derselben ein noch nicht untergegangenes Finnenbläschen herausdrücken liess, welches ganz die Charaktere hatte, wie sie den Finnen der Taenia mediocanellata jenes Fütterungstermines zukommen. 
III.

\section{Negatives Resultat der Trichinenfintterung beim Rinde.}

Durch die umfassenden Untersuchungen von Leuckart, Virchow und Zenker über Trichina spiralis sind wir belehrt worden, dass die geschlechtsreife Trichine den Darmkanal zahlreicher warmblütiger Thiere, besonders der Säugethiere, und zwar beständig in grosser Menge bewohnt, dass schon am zweiten Tage nach der Einwanderung die Darmtrichine ibre volle Geschlechtsreife erreicht, die Eier der weiblichen Darmtrichine sich in der Scheide der Mutter zu filarienartigen, winzigen Embryonen entwickeln, die vom sechsten Tage an ohne Eihülle geboren werden und sich alsbald auf die Wanderung begeben. Sie durchbohren die Wandungen des Darmkanales und gelangen durch die Leibeshöhle hindurch direkt in die Muskelhülle ihres Trägers, wo sie sich, falls die Bedingungen sonst günstig sind, zu der schon lange bekannten Form der Muskeltrichinen entwickeln.

Nach den Fütterungsversuchen von Leuckart bei den verschiedensten Säugethieren scheint der Hund für diesen 
Parasit weniger empfänglich zn sein, als das Schwein und das Kaninchen. Ein Versuch bei einem zwei Jahre alten Schafe lieferte ein negatives Resultat, insofern es nur gelang, am vierten Tage nach der Fütterung mit trichinigem Fleische in dem die Kothballen umhüllenden Schleime einzelne geschlechtsreife Darmtrichinen nachzuweisen, während sich später bei der in vierter Woche vorgenommenen Sektion keine Spur vou Muskeltrichinen fand.

Ganz besonders wünschenswerth erschien es schon Leuckart zu untersuchen, ob das bekanntlich so häutig als rohe Speise verordnete Rindfleis ch gelegentlich gleichfalls von Trichinen heimgesucht werde. Ein Experiment, das Leuckart angestellt hat, hatte nur bewiesen, dass sich die Muskeltrichinen im Darmkanal des Kalbes zu trächtigen Würmern entwickeln. Das Kalb, welches zum Versuche diente, erkrankte sieben Tage nach der Fütterung an Kolikschmerzen und Durchfall und starb am Abend des elften Tages. Bei der Sektion zeigte der Darmkanal ganz die gewöhnlichen Erscheinungen, abgestossene und zerfallene croupartige Membranen und eine starke Röthung des serösen Ueberzuges; aber Muskeltrichinen liessen sich nirgends nachweisen. Die Quantität des gefütterten Fleisches mochte wohl reichlich ein Pfund betragen haben.

Die hohe Wichtigkeit des Gegenstandes für sanitätspolizeiliche Maassregeln veranlasste mich, diesen Versuch bei einem Rinde in ausgedehntem Maasse zu wiederholen. Dasselbe wurde am 25. August 1863 mit 150 Grammes stark trichinigen, frischen Kaninchenfleisches gefüttert,

am 28. September wiederum mit 120 Grammes;

am 6. Oktober nochmals mit 100 Grammes solchen Kaninchenfleisches, 
am 13. Oktober mit 150 Grammes trichinigen Kaninchenfleisches,

am 22. Oktober mit 400 Grammes von in ungeheurer Zahl mit Trichinen durchsetzten Schweinefleisch, am 24. Oktober mit 300 Grammes Fleisch von demselben Thiere.

Indem ich die Wirkung des Benzins bei diesem Thiere an einer anderen Stelle besonders hervorheben werde, will ich hier nur bemerken, dass das Thier erst vom 8. Oktober an das Benzin erhalten, während die ersten Fütterungen mit trichinigem Kaninchenfleische schon am 25. August, am 28. September und am 6. Oktober Statt gehabt, wesshalb das negative Resultat unserer Fütterung nicht allein von dem Benzin hergeleitet werden darf. Bei der Sektion, die am 29. Oktober vorgenommen wurde, liessen sich nämlich bei der genauesten Untersuchung der Muskeln von verschiedenen Körperstellen dieses Rindes keine Muskeltrichinen auffinden, die doch, da die erste Fütterung bereits vor 2 Monaten Statt gehabt, vollkommen hätten entwickelt sein müssen, wenn sie unter Verhältnisse gekommen, die ihrer Entwicklung günstig gewesen wären. Es wird dadurch die Immunität des Rinder- und Ochsenfleisches für Muskeltrichinen aufs Neue bewiesen, und dürfen wir es diesem Umstande wohl zuschreiben, dass die Trichiniasis nicht noch häufiger die Menschen heimsucht.

Sehr überrascht war ich, auch in dem Darme dieses Rindes keine Darmtrichinen anzutreffen, trotzdem ich in Gemeinschaft mit Herrn Professor Leuckart den Darminhalt vielfach darauf untersucht habe. Da in dem oben erwähnten Fütterungsversuche von Leuckart die Darm- 
trichinen sich so massenhaft entwickelt hatten, dass das Thier an Enteritis trichinosa zu Grunde ging, glaubten wir mit Bestimmtheit annehmen zu dürfen, dass die Darmtrichinen insgesammt durch das Benzin getödtet und darnach mit dem Kothe nach Aussen entfernt worden sind. 
IV.

\section{Ueber die Pikrinsäure und ilıre Bedeutung als Anthelminthicum.}

Die Pikrinsäure bildet sich bei Einwirkung von Salpetersäure auf organische Substanzen, und namentlich auf. das Salicin und alle Spiroylkörper, Indigo, Steinkohlentheer, Cumarin, Xanthoreaharz etc. Das Steinkohlentheeröl, welches viel Phenylsäure enthält, eignet sich am Besten zur Darstellung der Pikrinsäure. Man vermischt alle bei der Bereitung des binitrophenylsauren Ammoniaks erhaltenen Mutterlaugen und zersetzt diese durch Salpetersäure; der sich bildende Niederschlag wird mit den braunen harzähnlichen Substanzen in einer Schale mit gewöhnlicher Salpetersäure übergossen und das Ganze bis zum Sieden erhitzt. Die beim Erkalten des Gemenges sich abscheidende Pikrinsäure wird mit etwas Wasser gewaschen, um die Salpetersäure zu entfernen, darauf mit Ammoniak gesättigt, filtrirt und das sich abscheidende Ammoniaksalz wiederholt umkrystallisirt. Wegen der geringen Löslichkeit des pikrinsauren Kali ist es besser, anstatt des Ammoniaks Kali anzuwenden. Das Ammoniaksalz wird in siedendem Alkohol gelöst; beim 
Erkalten der Flüssigkeit erhält man schöne Nadelı, die man durch Salpetersäure zersetzt.

Die aus Salicin dargestellte Pikrinsäure ist sehr rein und erfordert keine weitere Reinigung.

Man kann die Pikrinsäure auch, obwohl auf nicht vortheilhafte Weise, durch Kochen von Indigo mit 10-12 Theilen Salpetersäure von 1,43, bis sich keine rothen Dämpfe mehr entwickeln, darstellen. Beim Erkalten des Gemenges krystallisirt die Pikrinsäure helaus; man reinigt sie durch Auflösen in Aetzkali und Fällen durch Salpetersäure. Die Pikrinsäure krystallisirt gewöhnlich in hellgelben, stark glänzenden Schuppen; beim freiwilligen Verdunsten der Lösung erhält man sic oft in zolllangen, deutlichen Krystallen, an 2 Fcken oft stark abgestumpften Oktaedern. Sie schmeckt sehr bitter, etwas saller und röthet Lackmus. Sie löst sich in 160 Theilen Wasser bei $+5^{\circ}$; in 86 Theilen bei $+15^{\circ}$; in 81 Theilen bei $+20^{\circ}$; in 77 Theilen bei $+22,5^{\circ}$. Die Lösung ist gelber, als die feste Säure; sie färbt die Haut gelb. In Alkohol und Aether ist sie leicht löslich.

Die pikrinsauren Salze sind im Allgemeinen krystallisirbar, bitter und von gelber Farbe. Bei starkem Erhitzen, besonders in verschlossenen Gefässen, explodiren sie.

Die Pikrinsäure wird seit einiger Zeit in der SeidellFärberei angewendet. Sie giebt ein schönes Gelb.

Auch in der Medicin hat sie einige Anwendung gefunden. Professor Fr. Seitz (Dentsche Klinik 40, 1858) hat mehrfache physiologische Versuche angestellt, von welchen Folgendes zu erwähnen ist: Bei einem Kaninclien bewirkten 4 Gran Pikrinsäure, in Wasser gelöst, nach 15 Minuten eine Verlangsamung des Athmens auf 40 Athemzüge in einel Minute; später folgte weiche, dunkelgrïne Kothent- 
leerung. Der Harn wurde gelbröthlich. Am nächsten Morgen war das Thier todt gefunden. Es zeigte sich an dem Leichname eine beträchtliche Todtenstarre; die Conjunctiva Bulbi, die Umhüllungen des Gehirns, des Unterhautzellgewebes, die Muskeln und die Lungen waren intensiv gelb gefürbt; das Herz und die Abdominalvenen waren mit dunkelschwarzem, coagulirtem Blute überfüllt, die Magen- und Darmgefässe injicirt, die Oesophagus-, die Magenund Duodenalschleimhaut intensiv geröthet und mit dichtem gelbgefärbtem Schleime bedeckt. Die Leber und Milz waren blutreich, dunkelgefärbt, die Gallenblase von dunkelgelb rother Flüssigkeit ausgedelınt, die Nieren ebenfalls blutreich und dunkelroth gefärbt, in der Hamblase fand sich viel dunkelgelbrother Harn vor.

Bell*) in Manchester hat die Pikrinsäure zuerst gegen Wechselfieber angewendet, und ein gutes Surrogat für die Chinapräparate gefunden zu haben geglaubt. Die Salze werden der Säure selhst vorgezogen, weil letztere manchmal Magenkrampf veranlasst. Man hat namentlich das pikrinsaure Ammoniak und das pikrinsanre Eisen empfohlen. Moffat hat mehrere Fälle von Cephalalgie durch pikrinsaures Eisen und mehrere Fälle von Wechselfieber durch das entsprechende Ammoniaksalz geheilt. Er gab beide pikrinsaure Salze in Pillenform zu $\frac{1}{1}-\frac{1}{2}_{2}$ Gran 3 Mal täglich. Auch bei chronischen Diarthöen will Moffat vou den Salzen gute Erfolge gesehen haben. Er misst der Pikrinsäure tonische und adstringirende Wirkungen bei; auch hat er in mehreren Fällen eine leichte ikterische Fürbung der Haut und der Conjunctiva beobachtet.

*) II agen. Die seit 1830 in der Therapie eingefuihrten Arzneistoffe etc. pag. 131. 
Nachdem auch Braconnot und Calvert die Pikrinsäure gregen Wechselfieber mit ziemlich günstigem Erfolge angewandt hatten, versuchte Seitz das pikrinsaure Kali zu $S$ Gran in 4 zweigränigen Pulverdosen mit mindestens unsicherem Erfolge gegen Intermittens und hat dabei ebenfalls die bereits erwähnte ikterische Färbung $z u$ beobachten Gelegenheit gehabt. Das pikrinsaure Chinin erwies sich gan' wirkungslos gegen Wechselfieber.

Die anthelminthische Wirkung des Kali picronitricum wurde neuerdings von Professor Friedreich hervorgehoben. Da das Mittel sämmtliche Gewebe des Körpers rasch zu imprägniren scheint, überdies wegen seines stark bitteren Geschmackes lag der Gedanke nahe, dass es sowohl auf die im Darmkanal befindlichen, wie in den Muskeln und deren Zellgewebe abgelagerten Helminthen einzuwirken im Stande sei. Friedreich wandte das Mittel bei seinem mit Trichinen inficirten Kranken an, und bemerkte, dass bereits nach wenigen Tagen der Darreichung des Mittels die Erscheinungen rasch sich zurückzubilden begannen und von nun an der Kranke seiner Genesung entgegenging. Auffallend war es ferner dabei, dass bei der Herausnahme von Muskelstückchen nur das erste Mal eine grössere Zahl von Trichinen erhalten wurde, dagegen die späteren Male, obgleich die Präparate immer wieder aus demselben Muskel genommen wurden, theils keine, theils nur vereinzelte Thiere entdeckt werdell konnten. Ob dies zufällig war, oder ob etwa durch die Anwendung des Mittels der grösste Theil der Würmer getödtet, verflüssigt oder resorbirt worden sei, darüiber eine Meinung auszusprechen war Friedreich viel zu vorsichtig. Er lıat aber der Wichtigkeit des Gegenstandes wegen vorgeschlagen, die Versuche mit diesen Präparaten zunächst 
an trichinisirten Thieren vielfach $z u$ wiederholen; dieser Aufforderung ist durch Dr. Fiedler*) in Dresden bereits entsprochen worden, indem er bei einer grösseren Zall von trichinisirten Kaninchen dieses Mittel mit Beobachtung "aller erforderlichen Vorsichtsmaassregeln angewandt hat. Seine Resultate waren jedoch durchaus negativ und hat er sie kurz zusammengefasst:

1) Das Kali und Natron picronitricum tödtet, selbst in möglichst hoher Dosis gegeben, weder die Darm-, noch die Muskeltrichinen.

2) Es verhindert das Mittel die Einwanderang der Embryonen nicht und stört die Darmtrichinen in keiner Weise in ihrer Entwicklung.

Als mir diese Resultate von Fiedler bekannt wurden, war ich bereits mit meinen Untersuchungen über die anthelminthische Wirkung der Pikrinsäure beschäftigt; es hatten dieselben aber nicht blos die Trichinen, sondern auch die Tänien und Finnen zum Ziele. Was die ersteren anlangt, so waren die gründlichen Versuche von Dr. Fiedler so überzeugend für mich, dass ich bei trichinisirten Kaninchen keine weiteren Versuche mehr angestellt habe. Ich beschränkte mich darauf, als Controlversuch die Pikrinsäure nochmals bei einem trichinisirten Schweine zu erproben, da dasselbe nach früheren Versuchen von mir dies Mittel in sehr grosser Dosis zu vertragen im Stande ist.

Ich werde nun in Folgendem meine Resultate mittheilen

1) über die P'ikrinsäure als Bandwurmmittel,
2)
3) $\quad " \quad$,
\%
als Mittel gegen Finnen, als Mittel gegen Trichinen.

*) Virchow's Archiv. XXV1. 5. u. 6. pag. 573. 
Der Vollstïndigkeit wegen schicke ich einige Vorversnehe bei Kaninchen voraus, welche zum $Z$ wecke hatten, mich über die oben erwähnte physiologische Wirkung der Pikrinsäure zu belehren.

Forrersuche: Einem braunen, ausgewachsenen Kaninchen wurden ain 24. April 1863 Morgens 11 Uhr 2 Gran reine Pikrinsäure in Pulverform in Oblaten gehüllt eingegeben; Nachmittags $4 \mathrm{Uhr}$ abermals 3 Gran in Pillenform. Am anderen Morgen war das Thier todt. Es hatte sehr reichliche Diarrhöen gehabt.

Die am 25. April Morgens vorgenommene Autopsie zeigte das Unterhautzellgewebe und die Muskeln gelb gefärlbt. Ob auch das Blut eine gelbliche Färbung hatte, war schwierig zu entscheiden. Der Magen war mit Inhalt gefült, die Schleimhaut aufgelockert, nicht sehr blutreich, an der hinteren Wand der Cardia eine mehr als bohnengrosse Stelle schwarz gefärbt, wie angeätzt, ebenso noch einzelne Punkte am Fundus. Der ganze Darmtraktus war mit gelben Massen erfüllt, Schleimhaut mit gelbem, zähem Schleime bedeckt; Nieren sehr blutreich, das Becken gelblieh gefärbt, die geraden Harnkanälehen liessen vermehrten Zelleninhalt auspressen, die Harnblase war stark ausgedehnt, mit dunkelrothem Urine von saurer Reaktion erfüllt. Mikroskopiseh wurden darin zahlreiche Epithelien, die meist gelb gefärbt waren, und zahlreiche Cylinder mit dunkelkörnigem Inbalte nachgewiesen. Bei mikroskopischer Untersuchung der Malpighischen Glomeruli und der Harnkanälchen zeigteu sich zahlreiche Blutextravasate in das Lumen derselben abgesetzt; das Blut darin zu einer dunkelschwarzen körnigen Masse zerfallen. Leber sehr blutreich, weniger die Lungen.' Die parenchymatösen Organe, Leber und Nieren 
wurden schon nach kurzem Steheu an der Luft dunkelschwarz.

Einem jüngeren weissen Kaninchen wurden am 24. April Morgens 1 Gran Pikrinsäure in Pulverform, Mittags 2 Gran in Pillenform beigebracht. Das Pulver war ilım mit einem Glastrichter eingegossen worden, wobei wahrscheinlich von der nachspülenden Flüssigkeit ein Theil in die Lungen gekommen, indem es unmittelbar nachher asphyktische Zufälle zeigte. Es starb in der Nacht rom 25-26. April. Die Selition ergab das Unterhautzellgewebe gelb gefärbt. Sämmtliche Venen stark iiberfüllt. Der rechte obere Lungenlappen hepatisirt; der untere Lappen, sowie die linke Lunge stark lypperämisch. Herzhöhlen mit Blutgerinnseln erfüllt. Darmkanal ansgedehnt, Schleimhaut zeigte gelbe Färbung und katarrhalische Entzïndung. Die Nieren liatten dieselbe Veränderung, wie oben erwähnt, nur in geringerem Grade. -

Ein weisses Kaninchen, das in 5 Tagen rom 30. April bis 4. Mai 4 Gran Pilinäure erhalten, war gleichfalls davon gestorben. Die Muskeln waren bei dieser mehr chronischen Vergiftung gelber; Lungen und Herz normal. Nieren wieder auffallend blutreich.

Einem ausgewachsenen grauen Kaninchen wurde am 30. April Mittags 1 Uhr 1 Gran Kali picronitr. in Pulverform eingegeben;

am 1. Mai zu verschiedenen Zciten $=3$ Gran

am 2. und 3. Nai wurde pansirt;

$\begin{array}{llll}\text { am 4. Mai Mittags } 3 \text { Uhr } & =1 \text { Gran } \\ \text { am 9. Mai } " 2, & =2 " \\ \text { am 11. Mai } " 2, & =2 " \\ \text { am 12. Mai } " 2, & =2 \%\end{array}$

Im Ganzen waren es innerhalb 13 Tage $=11$ Gran. 
Tod an 13. Mai. Sektion zeigte geringere Färbung des Unterhautzellgewebes und der Muskeln, als bei reiner Pikrinsäure. Herz und Lungen normal. Mikroskopische Untersuchung des Blutes zeigte keine Veränderung der weissen und rothen Blutkörperchen. Darm aufgetrieben, enthielt reichliche, flüssige, gelbe Kothmassen, Schleimhaut von gelbem Sclleime bedeckt. Die Nieren hyperämisch, die Malpighischen Gefässknäuel mit Blutkörperchen überfüllt.

\section{Die Pikrinsäure als Bandwurmmittel.}

Da unter diesen Umständen die Wirkung des Mittels auf den Darmtraktus beschränkt bleiben soll, eine weitere Verbreitung desselben gar nicht erwünscht ist, wird es hier durchaus am Platze sein, stets das minder lösliche Präparat, das Kalisalz, wie es auch von Friedreich und Walter gebraucht wurde, zu wählen. In der Formel, wie sio Friedreich in Virchow's Archiv*) angegeben, habe ich das Mittel in folgenden Fällen versucht:

I. Fall. Gleichzeitiges Vorkommen ron 3 Bandwürmeru (Taenia solium). Hirnerscheinungen ohne Anwesenheit von Cysticerken im Gehirn. Heisshunger etc. 4 vergebliche Kuren mit Granatwurzelriude, Extractum Filicis und Kali picronitric. Endlicher Erfolg durch sehr energische Kux mit Kali picronitrieum.

Fräulein E. aus H. leidet seit $2:$ Jahren an heftigen Leibschmerzen; seit August 1862 Anfülle vou Angst, Kopfweh in der Stirne, unruhiger Schlaf. Sie wurde von ihrem Hausarzte an Bleichsucht behandelt, bis der Abgang von Proglottiden

*) 14 Kali picronitric. Dr. $\frac{1}{2}$.

Pulv. Rad. Jalappae Dr. 1.

Extract. Liq. q. s. ut f. Pil. No. 30.

DS. Träglich 3 Nial 5 Stück. 
entdeckt worden war. Darnach wurden zu zwei verschiedenen Zeiten Bandwurmkuren mit Granatwurzelrinde und Extrakt von Filix mas eingeleitet, olıne dass es gelungen war, den Kopf des Band wurmes abzutreiben.

Am 16. Januar 1863 erschien Patientin bei mir. Hauptklagen waren Kopfschmerzen, die Horgens gleich nach dem Aufstehen eintraten, durch Essen nicht gemindert wurden; grosse Angst, Schwerbesinnlichleit, Verwirrtheit der Ideen, Heisshunger, der sie alle Paar Stunden befiel, Schlaflosigkeit, mitunter Uebelkeit, ohne dass es zu Erbrechen kam. Die mitgebrachte Proglottide liess mich Taenia solium erkennen, wesshalb ich der Kopferscheinungen wegen alsbald an die Möglichkeit einer Selbstinfektion mit Cysticerken dachte. Da nach totaler Expulsion der Tänie die Hirnerscheinungen sistirten, habe ich diese Ansicht spïter fallen lassen.

Kur vom 17-20. Januar: Vorkur mit Aqua laxat. Vienens., Sauerkraut, 5 Häringen und Rothwein an 2 Tagen. Am 18. Januar 10 Uhr anf ein Mal 1 Dr. Extr. Filicis aether. in 1 Unc. Syr. simpl. genommen, wonach Mittags 3 Uhr ein Wurm abgegangen war.

In den überbrachten Bandwurmstïcken fand ich einen Kopf von Tänia solium, zugleich noch ein Halsstück, das nicht weit vom Kopfende abgerissen war. Patientin fühlte eine bedeutende Erleichterung von ihren Beschwerden; zur Nachkur wurden Pillen von Extr. Aloës mit Gutti verordnet.

Anfangs April waren wiederum Proglottiden abgegangen, wesshalb nunmehr eine Kur mit Pillen von Kali picro-nitric. begonnen wurde; die Vorkur blieb ganz die frühere mit Aqua laxat. Vienens. und sehr scharfen Speisen. Nachdem im Ganzen 25 Pillen verbraucht waren, wurden mir sehr grosse Stücke von Tänia solium überbracht, der Kopf fehlte indess. Patientin war durch die Kur mehr, als sonst angegriffen worden. Die früheren Beschwerden vom Wurme waren ganz verschwunden. Mitte Juli wurde abermals der Abgang von Proglottiden bemerlat. Am 19. Juli wurde desshalb die frühere Vorkur gebraucht; am 20. Juli wurden 15 Pillen von Kali picronitric. eingenommen, und am 21. Juli noch 5 Pillen, worauf etwa 20 dünne Stühle erfolgten; Bandwurmstücke gingen erst am 22. Juli Morgens \& Uhr ab. Eine genaue Untersuclıung liess darin noch keinen Kopf entlecken, wesshalb am 23. Juli Morgens nüchtern abermals 10 
Pillen und dariacli of Unc. Aqu laxat. Vienens. genommen wurden. Lin Liufe des Morgens ging ein Wurmkneuel ab, in dem nur wenige reife Proglottiden, dagegen 2 Köpfe von Tänia solium aufgefunden wurden. Dic Kur war selır angreifend gewesen. Es liatte das Kali picronitric. hier nicht in der raschen, von ihm gepriesenen Weise gewirkt, vielmehr erst dann, als zahlreiclie Unterstützungsmittel ihm beigegeben worden waren; und trotzdem war eine so grosse Dosis nöthig gewesun, dass deutliche Intoxikationserscheinungen, besonders von Seiten der Harnorgane zu Stande gekommen waren.

II. Fall von Taenia solium. Nach 2 vergeblichen Kuren mit Kusso und Granatwurzelrinde günstiger Erfolg von Kali picro-nitricum.

Madame R. ans Br. hat schon 2 Jahre Spuren eines Bandwurmes an sich bemerkt; vergebens waren inzwischen Kusso und Granatwurzelrinde gebraucht worden. Am 7. April wurde von mir eine Vorkur von Aqua laxat. Vienens. und scharfen Speisen verordnet; am 8. April Morgens nüchtern 2 Esslöffel von Aqua laxat. Vienens., um 8 Uhr 5 Pillen von Kali picronitric., worauf um 10 Uhr schon der Abgang des Wurmes erfolgte, an dem ein Kopf aufgefunden wurle. Die Dame ist tuberkulös, wurde desshalb von der Kur stärker angegriffen, erholte sich rasch wieder.

III. Fall von Taenia solium. Das Kali picro-nitricum wurde 2 Mal vergebens angewandt.

Georg B., 32 Jahre alt, aus Dudenhofen meldete sich bei mir am 12. April 1863 zur Abtreibung eines Bandwurmes. Proglottiden waren seit Herbst abgegangen; schon länger bemerkte er ein Blitzen vor dem rechten Auge, Schwindel und Angst. Mitte Deccmber wurde er zum ersten Male von epileptiformen Convulsionen befallen; sie kehrten alle $3-4$ Wochen wieder mit gleiclier Intensitit, waren im Ganzen schon 5 Mal eingetre- 
ten. Vergebens hat er schon 2 Mal eine Bandwurmkur gebraucht.

Kur: Am 13. und 14. April Genuss von rohem Sauerkraute, 3 Häringen, überhaupt von stark gesalzenen Speisen;

15. April Morgens und Abends je 4 Esslöffel von Aqua laxat Vienens. bei Fortgebrauch derselben Kost.

16. April. Morgens 7 und 11 Uhr und Mittags 8 Uhr je 5 Pillen von Kali picronitr. mit Rad. Jalappae, A bends 6 Uhr noch 2 Esslöffel von Aqua laxat.

17. April. Nochmals 2 Mal 5 Pilleı.

Am 18. April erschien Patient bei mir. Die Kur hatte ihn sehr angegriffen, besonders klagte er darüber, dass er sehr häufig habe uriniren müssen; auch habe der Harn eine sehr dunkelgelbe Farbe. Proglottiden waren indess trotz massenhaften Abführens nur sehr wenige abgegangen. Die Kur wurde darum in folgender Weise noch fortgesetzt:

Am 18. April Abends und 19. April Morgens je 4 Esslöffel von Aqua laxat. Vienens.

Am 19. April Morgens 9 und 10 Uhr je die Hälfte von folgender Mixtur (Extract. Filicis aeth. 1)r. 2 Syrupi simpl. Unc. 1.)

Am 20. April erschien der sehr gewissenhafte, zuverlässige Patient abermals, ohne dass Proglotticlen abgegangen waren, trotzdem er sehr stark abgefülırt hatte. Vorläufig pausirten wir mit der Kur; zur Stärkung wurde ihm China verordnet.

Am 16. August 1863 erschien Patient wieder mit der Angabe, dass er vor 4 Wochen den Abgang ron Bandwurmstücken beobachtet, ausserdem leide er an Bauchschmerzen, an Jucken im After; die Krämpfe seien alle $4-6$ Wochen wiedergekehrt. Sein Aussehen war sehr gut, Appetit vortrefflich. Es wurde nunmehr eine Wiederholung der Kur beschlossen.

Am 16. August nahm er ein Sennainfus. (von $\frac{1}{2}$ Unc. Fol. Sennae mit 2 Unc. Natr. sulph.) mit scharfen Speisen.

17. August Morgens 4 Esslöffel derselben Mixtur genommen; darnach 2stündl. 5 Pillen von Kali picronitr. und Rad. Jalappae, so dass an demselben Tage 30 Stück genommen wurden, worauf reichliche Ausleerungen erfolgten. Proglottiden waren darin nicht aufzufiuden. 
18. August Mlorgens noch 4 Esslöffel der Mixtur. Die ersten Proglottiden gingen in der Naclıt vom 18 -19. August, und ein grosses Bandwurmstïck am 19. August Morgens ab. In den mir bald überbrachten Nassen entdeckte ich 2 lange Halsstïcke ohne Köpfe. Patient war selır gelb und hatte so starke Besclswerden beim Uriniren, dass ein Fortgebrauch desselben Mittels contraindicirt war. Ich verordnete desshalb ein unschädlicheres Mittel: als Abführmiltel 0l. Ricini Unc. 2 mit 01. Crotonis Gtt. 2 ; und als Bandwurmmittel Extr. Filicis aeth. Dr. 1, Syrupi simpl. Unc. 1 Morgens nüchtern. Seitdem habe ich keine Nachricht vom $\mathrm{Pa}$ tienten erhalten.

IV. Fall. Die Wirkung des Kali picro-nitricum liess sich nicht genau angeben, da möglicher Weise vorher freiwilliger Abgang des ganzen Wurmes erfolgt war.

Wilhelmine D., 15 Jahre alt, aus Br., erschien Anfangs Juni bei mir mit Erscheinungen von Chlorose; sie hatte kolikartige Schmerzen, die anscheinend typisch auftraten, deutliche.Venengeräusche, bleiches Aussehen, überhaupt schwächliche Constitution. Da sie Tochter eines Metzgers ist, erkundigte ich mich alsbald nach Abgang von Proglottiden, worüber sie nichts berichten konnte.

Verordnung: Eisenpillen - China - laue Sitzbäder.

Am 18. August erschien Patientin wieder und referirte, dass ihr jene Mittel gut bekommen seien, dass insbesondere sich Mattigkeit und bleiches Aussehen verloren hätten. Die Menses waren noch nicht eingetreten; die Leibschmerzen kehrten öfters wieder, ohne dass sie genau bemerkt hatte, zu welcher Tageszeit am meisten. Die Bedeutung der Leibschmerzen wurde erst klar, als vor 2 Tagen Morgens, nachdem sie eine grössere Zahl saurer Aepfel gegessen, nach Vorausgang sehr intensiver Bauchschmer\%en der freiwillige Abgáng eines langen Stückes Bandwurm Statt hatte. Leider hat sie dasselbe nicht aufbewahrt; seine Existenz ist indess dadurch atisser Zweifel, dass ihr Vater früher selbst einen Bandwurm hatte und dadurch mit dem eigenthümlichen Aussehen desselben bekannt ist. Die Anamnese ergab auch weiter, dass das Mädchen von seinen Eltern früher zum Genuss von rohem 
Fleische angehalten worden war, damit es sich rascher entwickele nnd krïftige; wahrscheinlich hat sie den Wurm schon seit dem 9 ten Jahre, also während 6 Jahre bei sich gehabt, ohne dass für eine Tänie besonders charakteristische Zeichen vorhanden warell.

Die Kur wurde am 19. Angust begonnen mit Aqua laxat. Viellens; am folgenden Tage 2stündlich 3 Pillen von Kali picronitr., später Fortgebrauch von Aqua laxat.

Am 21. August berichtete mir Patientin, dass sie reichlich abgeführt, aber keine Spur von Bandwurmstücken bemerkt habe. Es wurde desshalb eine Kur von Ol. Ricini Unc. 2 init OI. Crotonis Gtt. 2 als Abführmittel, und nachher Extr. Filicis aeth. Dr. $1 \frac{2}{2}$, Syrupi simpl. Unc. 1 eingeleitet. Auch darauf erfolgte der Abgang des Wurmes nicht.

Die hier mitgetheilten Beobachtungen haben ergeben, dass die Pikrinsäure eben so wenig, als die bisher gebräuchlichen Kurmethoden ein ganz sicheres Mittel gegen Tänien ist, dass es bei ihr ganz derselben Vorkur bedarf durch stark gesalzene Speisen, welche dem Wurme widerlich sind, und durch Abführmittel, welche den Darmkanal entleeren. Die widersprechenden Ansichten der Aerzte bezüglich des Werthes der verschiedenen Bandwurmmittel haben darin ihren Grund, dass letztere meist nur dann von Erfolg sind, wenn sie zu einer Zeit angewandt werden, welche in Folge gewisser individueller Zustände der Tänie dem Abgange derselben besonders günstig ist. Welcher Art diese rlem Abgange der Tänie besonders günstigen Zustände sind, wann und wie oft dieselben eintreten, wie sie künstlich unter allen Umständen herbeigeführt werden kïnnen, darüber sind wir noch im Unklaren und besitzen wir darum anch noch kein ganz sicheres Mittel gegen die Tänien. Nach 
meinen bisherigen Erfahrungen wirken die gewöhnlichen Bandwurmmittel, insbesondere das Extractum Filicis aethereum, das Decoct der Granatwurzelrinde und Kusso gleich günstig, wenn sie zur Zeit des freiwilligen Abganges von Proglottiden gegeben werden; durch letzteres Momentzeigt sich nämlich die für die Abtreibung der Tänie günstige Disposition an. Vor dem Kali picro-nitricum, das, wenn es in dieser Periode angewandt wird, gleichfalls den gew ünschten Erfolg hat, verdienen indess die vorher genannten Mittel darum den Vorzug, weil sie nicht so angreifend sind, nicht so leicht schlimme Complicationen herbeiführen. Mein Rath geht desshalb dahin, mit diesem Bandwurmmittel besondere Vorsicht zu haben, es nicht bei Kindern oder schwächlichen Personen anzuwenden, insbesondere nicht bei solchen, die mit Nierenleiden behaftet sind oder dazu inkliniren, indem seine Anwendung leicht zu schlimmer Complication von Seiten der Harnorgane Veranlassung geben kann. Ausserdem wird die dadurch hervorgerufene gelbe Färbung *) der Haut nicht von jedem Patienten mit Gleichmuth hingenommen, wenn man ihm dafür nicht mit aller Bestimmtheit Befreiung von dem unangenehmen Gaste zusichern kann.

*) Merr Dr. Walter aus Offenbach, dem ich meine therapeutischen Versuclie mit Pikrinsäure mitgetheilt, schrieb mir am 2. November 1863, als Bestätigung meiner Ansicht: „Eine so intensive Färbung, wie ich sie bei dem veröffentlichten Falle gesehen, lässt sich das Publikum mit Recht niclit gefallen, wenn es zuletzt nichts nützt. Ich habe cinige Wochen lang eine Amylum-Glycerin-Mischung mit pikriusaurem Kali gegen Oxyuris in den Mastdarm spritzen lassen, rollkommen olne Erfolg; aber auch von da aus trat gelbliche Färbung ein." 


\section{Die Pikrinsäure als Mittel gegen Finnen.}

Da sich fast alle Gewebe des Körpers schon nach geringen Dosen der pikrinsauren Salze intensiv gelb färben, dieselben ausserdem einen sehr stark bitteren Geschmack haben, lag nach Friedreich's Vorschlag, dieselben gegen Tänien, so wie gegen Muskel- und Darmtrichinen anzuwenden, die Idee nahe, ob es nicht etwa möglich sei, durch Darreichung derselben das fernere Wachsthum der bereits in Entwicklung begriffenen Cysticerken zu beschränken, oder auch die auf der Wanderung begriffenen Embryonen zu vernichten. Da wir gegen die Finnenkrankheit noch ganz hülflos sind, schienen mir derartige Versuche von grosser Bedeutung.

$$
\text { Den ersten Versuch, }
$$

über den ich schon eine vorläufige Mittheilung in Virchow's Archiv*) gegeben, theile ich der Vollständigkeit wegen nochmals im Auszuge mit.

Einem gesunden, etwa 6 Wochen alten Schweinchen wurden am 25. April 150 reife Proglottiden von Taenia solium, am 15. Mai abermals 100 reife Proglottiden, und am 28. Mai 50 weitere Proglottiden gefüttert.

Um zu constatiren, ob die erste Fütterung (vom 25. April) den gewünschten Erfolg gehabt, wurde von mir am 28. Mai in Gemeinschaft mit Herrn Professor Leuckart eine Hautwunde am Halse angelegt, durch die wir unter dem Musculus sternothyreoideus eine Finne auffanden, an der man schon beim blossen Ansehen die Kopfanlage als hellen Fleck erkannte. Nachdem dieselbe vorsichtig aus-

*) Virchow's Mrehiv XXVIII. 3. и. 4. pag. 386. 
geschnitten, zeigte sie sich von oblonger Gestalt, etwa $3 \mathrm{Mm}$. lang. Nach Ansschälung ins der Kapsel erkinnten wir unter dem Mikroskop das Entwicklungsstadium der Finne als solches, wie es nach Leuckart's früheren Versuchen ungefihr unserem Fütterungstermine (34 Tage nach (ler ersten Fütterung) entsprechen musste; am nüchsten stand dasselbe derjenigen Entwicklungsstufe, wie sie von Lenckart in Figur 43. scines bekannten Werkes gezeichnet ist.

Um den Einfluss des Natron picro-nitricum auf diese sicher nachgewiesenen, in der Entwicklung begriffenen $\mathrm{Cy}$ sticerken zu erfahren, wurden mit allen Vorsichtsmaassregeln dem Thiere Pillen aus Natron picro-nitric. in folgenden Dosen eingebracht:

\begin{tabular}{|c|c|c|c|}
\hline 1. & Iuni & & 3 \\
\hline 2. & $n$ & & 2 \\
\hline 4. & $\eta$ & & 4 \\
\hline 5. & $"$ & & 3 \\
\hline 8. & $\eta$ & & 5 \\
\hline 10. & $n$ & & 5 \\
\hline 11. & $"$ & . & 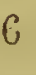 \\
\hline 12. & " & & 6 \\
\hline 13. & $"$ & & 6 \\
\hline 16. & $n$ & & 6 \\
\hline 20. & $"$ & & 6 \\
\hline 28. & $n$ & $\begin{array}{l}8 \text { Uhr M. } 1 \\
11 \text { Uhr M. } 1\end{array}$ & 2 \\
\hline
\end{tabular}

$\frac{29 .}{\text { Summe vom 1. bis 29. Juni }=98 \text { Gran Natron picro-nitr. }}$

Am 27. Juni habe ich in Gemeinschaft mit Herrn Professor Le uckart durch einen Hautsclinitt am Halse eine grosse Zahl reifer Cysticerken aufgefunden, die in ihrer Entwicklung durch das Arzneimittel nicht aufgehalten worden waren. 
Von der letzten Fütterung (15. und 28. Mai) lierrührende Finnen konnten keine aufgefunden werden. Um hierüber zu sicherem Resultate zu gelangen, war es nöthig, das Schwein in den nächsten Tagen zu schlachten, indem immerhin noch an die Möglichkeit gedacht werden konnte, dass die auf der. Wanderung begriffenen Embryonen durch das Natron picro-nitricum vernichtet worden waren, wiewohl es festgestellt war, dass auf die bereits in der Entwicklung begriffenen Finnen dadurch nicht influirt worden war.

Dabei habe ich die Gelegenheit benutzt, zu constatiren, wie viel das Schwein von reiner Pikrinsäure, die bei Kaninchen so entschieden toxische Wirkung hatte, vertragen könne. Das Thier erhielt daher am

1. Juli 18 Gran reine Pikrinsäure,

2. " 20 " "

3. $\quad 40 \quad " \quad$,

in 3 Tagen 78 Gran reine Pikrinsäure.

Das Thier war darnach sehr abgemagert, hatte höliere Temperatur der Haut, zeigte Brechbewegungen, dagegen frass es noch mit derselben Gier. Am 4. Juli Morgens 7 Uhr wurde es in der Aethernarkose mit Lufteinblasen in eine Vene getödtet. Die Sektion ergab die folgenden Befunde:

Im Gehiru wurden im Ganzen 5 Finnen aufgefunden, 3 an der Oberfläche zwischen den Gyri, 2 in den Seitenventrikelu. Im Vergleich mit den Finnen anderer Regionen, besonders in den Muskeln, waren sie kleiner an Umfang, doch der Kopf vollständig entwickelt. Ihr Inhalt war ebenso, wie der sämmtlicher vou mir untersuchter Finnen vollkonmen hell, klar, keineswegs von Pikrinsäure gelb gefärbt. 
Mundhöhle stark gelb gefärbt; in der Zungensubstanz liessen sich kciue Fimnen auffinden; säınıntliche Muskeln des Halses mit Finnen durehsetzt, mehr die tieferen in der Nähe der Wirbelsäule, als die oberflächlichen; die Brustmuskeln gleichfalls reichlich durchsät. An beiden Seiten der inneren Thoraxwand waren die lnterkostalmuskeln vielfach von Finnen durchsetzt; sie repräsentirten sich als längliche helle Blasen mit deutlich markirtem weissem Kerne.

Die beiden Blätter des Herzbeutels zeigten einzelne deutlich ausgebildete Finnen, weniger in dem oburflächlichen, als in dem visceralen Blatte, wo etwa $12-15$ Blasen an der Oberfläche des Herzens deutlich hervorragten.

Herzsubstanz selbst, so wie die Klappen, nicht verändert. Lungen in den vorderen Partieen empliysematös, in den hinteren blutreich. Auf der Oberfäche der hinteren Flächen etwa 20-30 Finnen bemerkbar, während die Lungensubstanz selbst frei davon war. Dagegen fanden sich an den unteren Lappen beiderseits 2 etwa taubeneigrosse verdichtete Stellen, die sich als Pneumonia verminosa von Strongylus paradoxus ergaben. Im Zwerehfell und dell Bauchmuskeln waren die Finnen noch zahlreicher, als in den Hals- und Brustmuskeln. Schleimhaut des Oesophagus gelb gefärbt; in der Muskulatur einzelne Finnen.

Magen stark ausgedehnt mit reichlichem Speiseinhalt; Schleimhaut gelb gefärbt, zeigte an der hinteren unteren Partie massenhafte Erosionen älteren und jüngeren Datums; am deutlichsten war die gelbe Imbibition der Schleimhaut mit Pikrinsäure am Pylorusmagen und von da durch das Duodenum bis an das Jejunum. Es hatte die Schleimhaut hier Bronzefarbe, war mit zähem Schleim bedeckt, zcigte zahlrciche erwciterte Gefässe, in denen das Blut stagnirte. An den tieferen Stellen des Dünndarmes war die Fïrbung: 
nicht so intensiv, überall indess weit vorgeschrittener Katarrh der Schleimlıaut. Darminhalt dünn, gelb gefärbt. Die tiefsten Partieen des Dünndarmes, so wie des Dickdarmes durch zahlreicle frisclie peritoneale Adhäsionen verwachsen, wie überhaupt das Peritoneum grossentheils an der Entzündung Theil genommen. Es war stark hyperämisch, an vielen Stellen trübe, sämmtliche Mesenterialdrüsen gescliwellt.

Dickdarmschleimhaut zeigte an einzelnen Stellen hochgradige, katarrhalische Affection, an anderen ausgebildete Enteritis follicularis, an den meist afficirten Stellen ausgesprochene croupöse Auflagerungen. Es reichte die Affection bis in das Rectum hinab.

Von sämmtlichen nicht muskulösen inneren Organen zeigte die Leber die meisten Finnen sowohl an der Oberfäche, wie auch im Innern. Sie war gross, stark hyperämisch. Milz ohne Finnen, desgleichen die Nieren und Geschlechtsorgane. Nieren etwas vergrössert, hatten sämmtliche Zeichen katarrhalischer Nephritis. Auch die Uretheren- und Harnblasenschleimhaut zeigte deutliche katarrhalische Affection, insbesondere war letztere intensiv gelb gefärbt. Der aus der Harnblase genommene Urin war dunkelroth, schwach sauer; durch Kochen wurde reichlich Eiweiss ausgefällt. Mikroskopisch fanden sich darin einzelne Blutkörperchen, fettig zerfallene Epithelien, zahlreiche Fetttropfen, gelblich gefärbte Massen von Detritus.

Die genauere Untersuchung der Finnen ergab dieselben nach Grösse, Form und Entwicklung des Kopfes vollkommen ausgebildet; etwa 5-7 Mm. lang, 3-4 Mm. breit; es war daran weder eine Trübung des Körperparenchyms, noch eine Resorption und Eindickung ihrer Flüssigkeit bemerkbar, wie sie bei abgestorbenen oder in ihrer Entwick- 
lung gehemmten Finnen wahrgenommen wird. In sehr geringer Zull wurden bei genanerem Nachsuchen auch einige kleinere Finnen von 1,j-- 2 Mm. mit eben gebildetem Kopfzapten, die wohl von der späteren Fütterung herrübren mochten, aufgefundein.

Aus vorstehend mitgetheiltem Versuche lassen sich folgende Schlüsse zielıen:

a) Das Natron picro-nitricum war nicht im Stande, die weitere Entwicklung der durch die erste Fütterung erzielten Finnen in ihrer Entwicklung aufzuhalten; auch habendiezuletzt gereichten grossen Gaben reiner Pikrinsäure keinen deletären Einfluss auf die ausgebildeten Finnen geäussert.

b) Fraglich ist es bei unserem Experimente geblieben, ob die zweite und dritte Fütterung durch Anwendung der Pikrinsäure gestört worden ist, resp. ob die auf der Wanderung begriffenen Embryonen dadurch theilweise vernichtet wurden. Faktisch ist, dass wir von den durch spätere Fütterung erzielten Finnen nur wenige auffinden konnten. Es wäre denkbar, dass dies negative Resultat von anderen individuellen Verhältnissen abhängig war, weshalb bei Wiederholung des Versuches diesem Punkte besondere Aufmerksamkeit zu schenken war.

c) Die grossen Dosen von Natron picro-nitricum (98 Gran) und zuletzt von reiner Pikrinsäure (78 Gran), welche von dem Schweine ohne sehr rasch erfolgte Intoxication vertragen wurden, beweisen, dass dasselbe gegen diese Präparate eine viel bedeutendere Renitenz lı at, wie diejenigen Thiere, die bis dahinzusolchen Versuchen benutzt w orden sind (Hundend Kaninchen).

Betrefts der Wirkung dieser Präparate inf die inneren 
Organe war besonders interessant die lochgradige bis zur Dysenterie gesteigerte Darmaffection, so wio die hochgradige entzündliche Affection der Harnwege.

d) Durch unseren Versuch ist schliesslich wiederholt auf experimentellem Wege dic Identität der Schweinefinne mit dem gemeinen Menschenbaudwurme bewiesen worden, dadurch, dass es gelungen ist, den Cysticercus aus den Eiern der Taenia solium zu entwickeln, insbesondere da der Entwicklungsgrad der Finnen mit der Entfernung von dem Fütterungstermine immer vollständiger wurde.

\section{Zweiter Versuch.}

Freitag den 10. und Sonnabend den 11. Juli 1863 wurden einem etwa 7 Wochen alten Sclnweinchen zahlreiche Glieder von Taenia solium gefüttert. Ich muss erwähnen, dass dies eine der oben erwähnten zweifelhaften Formen war, die ihrer massigen Uterinverzweigungen, und der bedeutenderen Breite der Glieder wegen anfangs für Taenia mediocanellata, ihrem ganzen Habitus nach dennoclı für Taenia solium gehalten werden musste. Um auf die Wanderung der Embryonen einzuwirken, wurde das Natron picro-nitricum sehr bald nach der Fütterung gegeben.

Sonntag den 12. Juli erhielt das Thier 12 Gran,

\begin{tabular}{|c|c|c|c|c|c|c|}
\hline den 13. & $"$ & $"$ & " & " & 12 & " \\
\hline den 14 & " & $r$ & 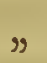 & " & 24 & g \\
\hline en 15 . & " & " & " & ” & 12 & $\eta$ \\
\hline
\end{tabular}

Eine $z$ weite Fütterung mit Taenia soliun fand bei demselben Schweinchen am 25. Juli Statt. Es erhielt 84 reife Proglotticlen. 
Am 26. Juli wurden ihm 20 Gran Natron picro-nitric., eingegeben.

$20 \%$

Eine $d$ ritte Fütterung mit 70 reifen Proglottiden von Taenia solium fand an 4. August Statt. Am 6. und 7. August wurde das Thier ausserdem noch mit 300 Grammes Kaninclienfleisch, in dem selı viele Muskeltrichinen waren, gefüttert. In Folge von Enteritis trichinosa starb das Thier schon am 11. August. Auf diesen durch die Trichinenfütterung herbeigeführten exitus lethalis, den ich an einem anderen Orte genauer besprechen werde, hatte wohl die damals herrschende Hitze mit eingewirkt.

Bei der Section habe ich in Gemeinschaft mit Herrn Professor Leuckart die Muskeln sehr genau auf die Anwesenheit von Finnen untersucht. Es gelang uns uur sehr wenige im Zwerchfelle aufzufinden, während die Halsmuskeln, das Herz etc. ganz frei davon waren. Es wurden im Zwerchfelle eine grössere Finne mit durchleuchtendem Kopfe und einige kleinere mit eben in der Entwicklung begriffenen Kopfzapfen gefunden, welche beide Arten gewiss von verschiedenen Fütterungsterminen abstammten. Obgleich noch zahlreiche andere Muskeln gründlich unter der Loupe durchsucht wurden, waren darin keine Finnen mehr zu entdecken.

Es konnte nach diesem Resultate an die Möglichkeit gedacht werden, dass auf die in Wanderung begriffenen Embryonen durch die grossen Gaben von Natron picro-nitricum, die beide Male 24 Stunden nach der Fütterung mit Taenia solium gereicht worden waren, ein deletärer Einfluss ausgeübt worden sei, zumal dies auclı bei dem vorigen Versuche nicht unwahrscheinlich schien.

Da andererseits immer noch angenonmen werdeu konnte, dass durch gewisse individuelle Einflüsse die 
Wanderung und weitere Entwickelung der Bandwurmembryonen zu Finnen nicht stattgehabt, schien mir eine Wiederholung der Versuche zur endlichen Bestätigung immer noch wïnschenswerth.

\section{Dritter Versuch.}

Einem 6 Monate alten Schweine wurden au 15. Oktober 1863, nachdem es an den letzten 5 Tagen vorher in kleineren Dosen vertheilt zusammen eine Drachme Natron picro-nitricum erhalten, 180 reife Proglottiden der Taenia solium gefüttert, und am 16. Oktober gleichfalls 100 reife Proglottiden. In der nächsten Zeit nach der Fütterung bis zum 22. Oktober erhielt das Thier abermals 2 Drachmen Natron picro-nitricum. Am 22. Oktober. Abends war dasselbe an der Pikrinsäure gestorben. Besondere Umstände hatten es nicht gestattet, den Versuch länger hinauszuziehen.

Wie ich zum Voraus vermuthete, war es nicht möglich; in dieser frühen Periode, erst 8 Tage nach der Fütterung, die ersten Stadien der Finnenbildung aufzufinden, und konnte ich somit auch durch diesen Versuch die Frage nicht entscheiden, ob durch Anwendung der Pikrinsäure die auf der Wanderung begriffenen Embryonen vernichtet werden. Jenes negative Resultat der Pikrinsäure zuzuschreiben, würde gewagt sein, indem auch von Leuckart die frühen Entwicklungsstufen der Schweinefinne trotz aller Bemühungen bei früheren Versuchen nicht aufgefunden werden konnten. Einigen seiner Versuchsthiere hatte er 8 und 10 Tage nach der Infection mit Tänieneiern Muskelmassen ausgeschnitten, auch einmal am 12. und 14. Tage nach der Fütterung ein ganzes Schweinchen sorgfältig untersucht, aber immer vergebens. 


\section{Nachschrift.}

Bei einer nachträglichen, sehr genauen Untersuchung des Herzens, indem es mich zunächst interessirte, ob Muskeltrichinen, mit denen das Thier gleichzeitig gefüttert worden war, darin zu finden seien, was indessen nicht der Fall war ${ }^{*}$ ), ist es mir bei einer 350 fachen Vergrösserung gelungen, ovale Bläschen von 0,032946 Mm. Länge und 0,024276 Mm. Breite mit körnigem Inhalte aufzufinden, welche ich unter den gegebenen Verhältnissen als die ersten Anfänge der Finnenbildung ansprechen zu dürfen glaube. Ich habe in dem mit schwacher Kalilösung und Glycerin behandelten Muskelfleische des Herzens eine grössere Zahl aufgefunden. Eine eigentliche Kapsel habe ich daran nicht aufgefunden; sie lagen ganz frei zwischen den Muskeln. Es sind die kleinsten Finnen, welche bis dahin gefunden worden sind. Die kleinsten, welche Leuckart untersucht hat, waren Bläschen von $1 \mathrm{Mm}$. Länge und $0,7 \mathbf{M m}$. Breite. Sie stammten von Schweinen, die 30 und 32 Tage vorher mit Bandwürmern inficirt waren. Durch unsern Fund werden Rainey's Beobachtungen iiber die ersten

*) Ich habe sehr oft bei Thieren, die reichlich trichinisirt waren, das Herz auf die Gegenwart von Muskeltrichinen geprüft, immer mit negativem Resultate. Ein Gleiches muss ich behaupten bezüglich meiuer Nachforschungen nach Muskeltrichinen in der Uterussubstanz; auch habe ich mehrfach trächtige Kaninchen mit Trichinenfleisch gefüttert, und später in den Muskeln.der Embryonen nach Trichinen gesucht; bis jetzt waren aber alle diese Bemilhungen fruchtlos. 
Zustände des Cysticercus cellulosae direkt widerlegt. Hiernach sollten die Schweinefinnen anfangs in Form eines spindelförmigen Schlauches im Innern eines Muskelbündels gelegen sein und durch Platzen desselben in die umhüllende Bindesubstanz übertreten. Die genauere Beschreibung der Rainey'schen Beobachtung findet sich in Leuckart's Werk: Ueber die menschlichen Parasiten pag. 238, wobei das häufige Vorkommen der Rain ey'schen Schläuche bei Schafen und Schweinen, die nicht mit Taenia solium gefüttert, und was die eigentliche Natur derselben anlangt, ihre Uebereinstimmung mit den sogenannten Psorospermiensäcken erwähnt wird.

Durch Auffinden der oben erwähnten Bläschen wird schliesslich die Nutzlosigkeit der Pikrinsäure gegen Einwanderung der Embryonen von Taenia solium und deren Entwicklung zu Finnen auf das Entschiedenste dargethan. Es hat sich hiernach die Pikrinsäure gegen Finnen vollkommen unwirksam gezeigt.

3. Die Pikrinsäure als Mittel gegen Trichinen.

Wie bereits oben erwähnt wurde, habe ich mich darauf beschränkt, als Controlversuch der Fiedler'schen Experimente die Pikrinsäure bei einem trichinisirten Schweine zu erproben, da dasselbe nach den vorerwähnten Beobachtungen dies Mittel in sehr grossen Gaben zu vertragen im Stande ist.

Einem 5 Monate alten, gesunden Schweine wurde am 
7. und am 28. September 1863 eine grössere Portion trichinigen Kaninchenfleisches gefüttert. Ein Gleiches geschah am 7. Oktober. Am 10. Oktober wurde dem Thiere zum ersten Male ein Scrupel Natron picro-nitricum in Lösung eingegossen. Das Thier war darnach matt, lag ruhig dahin, hatte sich am Mittag wieder erholt. An den folgenden vier Tagen liess ich ihm jedes Mal nur 10 Gran Natron picronitricum in Lösung eingiessen; am 15. Oktober wieder einen Scrupel, und am 16. Oktober 10 Gran.

Am 17., 18., 19., 20. und 21. Oktober wurden je 18 Gran Natron picro-nitricum in Pillenform (von 3 Gran die Pille) gegeben. Am 22. Oktober starb das Thier, nachdem es im Verlauf von 12 Tagen im Ganzen 3 Drachmen Natron picro-nitricum erhalten hatte.

Die Section wurde am 23. und 24. Oktober vorgenommen. Muskelstarre nicht vorhanden, hochgradige Abmagerung, die äussere Haut, das Unterhautzellgewebe, die Muskeln stark gelb gefärbt, in dem Herzbentel, im Brustfellund Bauchfellsacke gelb gefärbte Flüssigkeit angesammelt. Auch die Schädeldecken, die weichen sowohl, wie die harten, zeigten gelbe Färbung. Hirnhäute hyperämisch, gelb gefärbt, auch die Oberfläche der Hirnsubstanz liatte noch eine solche Färbung, während dagegen die inneren Partieen des Gehirnes keine Veränderung der Farbe aufwiesen. Consistenz des Gehirnes normal. Rückenmarkshäute und Rückenmark selbst zeigten dieselben Befunde. Schleimhaut der Mundhöhle, der Speiseröhre und des Magens intensiv dunkel gefärbt; die Schleimhaut des Magens insbesondere schr verdickt, liess sich mit Leichtigkeit von dem submukösen Bindegewebe abziehen. Der Darm enthielt flüssigen, schleimigen, dunkel bräunlichen Inhalt; die Schleimhaut nicht 
auffallend gelb gefärbt, hatte ein schmutzig graues Aussehen, wie überhaupt alle Zeichen vorausgegangenen Katarrhes. Besonders fielen daran zahlreiche grössere und kleinere pigmentirte ulcerirte Stellen auf, von denen die grösseren der Länge des Darmes entlang waren; mikroskopisch fanden sich beim Abschaben derselben zahlreiche runde Pigmentzellen, Eiterkörperchen, Blutkrystalle, Epithelzellen.

Das Peritoneum hyperämisch, die Mesenterialdrïsen vielfach stark intumescirt, geröthet; einzelne Darmstïcke durch ältere und jüngere Adhäsionen verwachsen. Leber sehr blutreich, dunkel gefärbt, dessgleichen die Milz. Nieren beiderseits dunkel gefärbt, derb, aus den Papillen katarrhalisches Sekret auszudrïcken; Uretheren und Schleimhaut der Harnblase gelblich gefärbt, das Epithel von letzterer aufgelockert. Urin dunkelbraunroth, enthielt eine geringe Spur von Eiweiss. Kehlkopfschleimhaut von gelblich rothem Aussehen, Trachealschleimhaut intensiv gelb gefärbt, die Bronchien bis in die kleinsten Verzweigungen mit reichlich schaumigem gelbem Sekrete erfüllt. Lungen überall lufthaltig, zeigten gleichfalls gelbliche Färbung. Herzfleisch weniger gelb gefärbt, als die übrigen Muskeln, in den Herzhöhlen dunkelrothe, feste Gerinnsel. Klappen zart, von normaler Färbung.

Die genauere Untersuchung der willkürlichen Muskeln zeigte sehr zahlreiche, eben in der Einkapselung begriffene, so wie kleinere, noch freie Trichinen, die sich beim Erwärmen lebhaft bewegten; im Darmkanal fand sich gleichfalls eine Anzabl von Darmtrichinen, die sich noch bewegten.

Es bewoist dieser Versuch anf Neue, dass 
das Natron picro-nitricum, selbst in sehr grosser Dosis gogeben, weder die Darmtrichinen, noch die Muskeltrichinen tödtet, noch auch die Einwanderung der Embryonen verhindert. Wir stimmen deshalb mit Fiedler überein, dass sich die fernere Anwendung dieses Mittels bei der Trichinenkrankheit nicht mehr rechtfertigen lässt. 
V.

\section{Ueber das Benzin nud seine anthelmintlische Wirkung.}

Benzin (Benzol, Phenylwasserstoff) wurde von $\mathrm{Fa}$ raday im Jahre 1825 entdeckt. Es entsteht bei vielen Zersetzungen organischer Körper, besonders in der Hitze. Einfache Verwandlungen, in welchen Benzin auftritt, sind folgende. Bei der Destillation ron Benzoësäure mit überschüssigem Kalkhydrat (Mitscherlich) oder beim Leiten der Dämpfe von Benzoësäure über glühendes Eisen (Darcet). Die Destillation von Phtalsäure über Aetzkalk giebt ebenfalls Benzol (Marignac). Ferner erhält man es bei der Destillation der Insolinsäure über Aetzbaryt, wobei ein verkohlter Rückstand bleibt (Hofmann). Auch bei der trockenen Destillation der Chinasäure entsteht Benzol (Woehler), ebenso wenn man Fette durch glühende Röhren leitet (Faraday), oder bei der trockenen Destillation der Steinkohlen, und findet sich daher in dem flüchtigeren Theil des Steinkohlentheers (Hofmann, Mansfield); ferner wenn man Bergamottöldämpfe durch glühende, mit Kalk gefüllte Röhren leitet $(0 \mathrm{hme})$; selbst wenn Essigsäure 
oder Alkohol dampfförmig durch glühende Röhren geleitet werden, tritt etwas Benzol auf (Berthelot). Es findet sich im Erdöl von Burmah, dem sogell. Rangoon - Theer (Warren de la Rue und Müller). Zur Darstellung von reinem Benzol wendet man entweder reine Benzoësäure an, oder man gewinnt es aus dem leichten Steinkohlentheeröl. Das Benzin ist bei gewöhulicher Temperatur eine farblose, dünnflüssige Flüssigkeit, deren specifisches Gewicht bei $15,5^{\circ} \mathrm{C} .=0,85$ (Faraday, Mitscherlich), bei $0^{\circ}=$ 0,8991 (Kopp) beträgt. In der Kälte erstarrt es entweder in farrenkrautähnlichen vereinigten Blättern oder ähnlich wie Campher. Bei $-18^{\circ} \mathrm{C}$. ist es hart, spröde und pulverisirbar von $0,956 \mathrm{spec}$. Gewicht; es schmilzt bei $5,5^{\circ} \mathrm{C}$., wobei sein Volumen sich um $\frac{1}{8}$ vermehrt, und gesteht wieder bei $0^{\circ}$. Es siedet bei $80,4^{\circ}$ C. - In Wasser ist das Benzin unlöslich, theilt ihm jedoch Geruch mit, in Weingeist, Holzgeist, Aceton und Aether sehr leicht löslich. Es löst etwas Schwefel, Phosphor und Jod, in der Wärme mehr, als in der Kälte; es löst leicht fette und ätherische Oele, Campher, Wachs, Cautschuk und Gutta-Percha, ziemlich leicht löst es Chinin, wenig Morphin und Strychnin, aber kein Cinchonin (Mansfield).

Das Benzin lässt sich über Kalium, Kalihydrat, Phosphorchlorid, und zum Theil über concentrirte Schwefelsäure ohne Veränderung destilliren. Angezündet brennt es mit leuchtender, rusender Flamme. Ein Gemenge von 1 Vol. Benzin und 2 Vol. Spiritus (von 85 Procent Alkohol) giebt beim Verbrennen in Lampen ein schönes Licht; bei grösserem Benzingehalt rust die Lampe. Leitet man Benzindampf durch eine rothglühende Röhre, so entsteht unter Abscheidung von Kohle ein gasförmiger Kohlenwasserstoff.

Durch Chlor wird das Benzol nur im Sonnenlicht an- 
gegriffen und in Chlorwasserstoff - Chlorbenzol verwandelt; älnnlich verhält sich Brom. Jod hat selbst im Sonnenlichte keine Einwirkung.

Concentrirte Salpetersäure verwandelt das Benzol in Nitro-Benzol, verdünnte Salpetersäure bewirkt bei anhaltendem Kochen dieselbe Verwandlung.

Rauchende Schwefelsäure verwandelt das Benzol in Sulphobenzid und Sulphophenylsäure; concentrirte Schwefelsäure löst Benzol unter Bildung des letzten Produktes allein (Gerhardt). Nach Mitscherlich und Mansfield ist concentrirte Schwefelsäure ohne Wirkung auf Benzol. Wässerige Chromsäure, sowie Chlorkohlenoxydgas im Sonnenlicht, verändern das Benzol nicht. Als nähere Bestandtheile des Benzins werden Phenyl, $\mathrm{C}_{12} \mathrm{H}_{5}$ und Wasserstoff angesehen, so dass die rationelle Formel $\mathrm{C}_{12} \underset{\mathrm{H}}{\mathrm{H}}$ \} geschrieben wird. *)

Das unreine, aus Steinkohlentheeröl im Grossen erhaltene Benzin wird für sich, zuweilen gemengt mit Aether, als Fleckwasser angewendet.

In der Heilkunde wurde es bisher bloss äusserlich benutzt, da man es für giftig hielt. Milne Edwards machte zuerst anf die Eigenschaft dieses Stoffes, Insekten zu tödten, aufmerksam. Reynal versuchte dasselbe bei den durch Parasiten bedingten Hautkrankheiten unserer Hausthiere und veröffentlichte die erhaltenen Resultate im Recueil de med. vet. 1854. p. 258. Obschon die Thierheilkunde nicht wenige Mittel bẹsitzt,

*) Irandwörterbuch der reinen und angewandten Chemie von Lie big, Poggendorf und Woehler. Il. 1. p. 870. Braunschweig 1859. 
diese Epizoen zu tödten, so haben doch diese meist gleichzeitig nicht zu übersehende Uebelstände. So wirkt z. B. die Merkursalbe bei Fleischfressern und Wiederkäuern leicht nachtheilig, indem sie Allgemeinerscheinungen hervorruft; das Terpenthinöl reizt bei allen Thieren, besonders aber beim Hunde sehr stark; die Tabakslange, die Tabakabkochung, die Jodtinktur u. a. m. beschmutzen die Haut und die Haare und erfordern gewisse Vorsichtsmaassregeln, die von den Personen, die die Anwendung dieser Mittel zu besorgen haben, nicht selten aus dem Auge gelassen werden. Von allen diesen Unzukömmlichkeiten ist das Benzin frei; es wirkt schnell und sicher, lässt sich leicht anwenden, verdunstet sehr rasch, ohne auf die Gewebe selbst einzuwirken, und kann daher selbst auf ausgedehntere Partieen der Körperoberfläche ohne Nachtheil benutzt werden.

Reynal stellte über die tödtende Eigenschaft des Benzins verschiedenartige Versuche an. Zecken, Haarlinge, Hühnerläuse starben sogleich, nachdem dieselben in Benzin gebracht oder mit einem in diese Substanz getauchten Glasstäbchen berührt worden, und zwar trat der Tod rascher ein, als bei der in gleicher Weise unternommenen Anwendung des Terpenthinöls, des Lavendelöls und der Tabakabkochung.

Bei zwei Pferden und bei einem Esel, welche eine Unzahl Läuse hatten, wurde Benzin gegen den Strich init der Hand eingerieben; binnen wenigen Minuten waren diese Epizoen sämmtlich todt; einen gleichen Erfolg ergab die Anwendung dieses Mittels bei zwei mit zahlreichen Zecken behafteten Hunden. Bei einem der letztgenannten Thiere wurde gleichzeitig des Vergleiches wegen Terpenthinöl angewendet, welches zwar die Zecken tödtete, dagegen eine heftige Hautentzündung hervorrief, während das Benzin die 
Haut unverändert liess. Auch bei drei Schweinen, deren Körper mit zahlreichen Läusen besetzt war, erfolgte die gründliche Beseitigung dieser Parasiten durch das Benzin in kürzester Zeit; stärkere Befeuchtungen des Rüssels, der Obren, der Gegend um die Augen hatten auf die Haut durchaus keinen nachtheiligen Einfluss; ein von Haarlingen und Läusen geplagter, gegen 2 Jahre alter Stier wurde eben so rasch mittelst des Benzins seine Schmarotzer los. Bei einem Pferde, auf dessen Körper in Folge der Unterbringung von Hühnern in demselben Stalle zahlreiche Hühnerläuse (Dermanyssus avium) sich eingefunden hatten, und welches durch diese Epizoen zu einem unausgesetzten Reiben und Nagen veranlasst wurde, reichte eine zweimalige Einreibung von Benzin (100 Granımes) zur vollständigen Heilung hin. Aus den eben angeführten Versuchen ergiebt sich, dass alle Epizoen durch das Benzin längstens binnen 10 Minuten getödtet werden; die Menge des verbrauchten Materiales ist nach der Thiergattung und nach der Art der Parasiten verschieden, meist reichen jedoch bei einem Pferde 100, bei einem Hunde 20 Grammes hin.

Zur Tödtung von Zecken wird mehr, als zu jener der Läuse und Haarlinge verwendet.

Eine dritte Reilue der von Reynal angestellten Versuche hatte den Zweck, zu erforschen, ob das in Dampfform angewendete Benzin eben so rasch die Parasiten tödte, als das flüssige, und welche Wirkung diese Dämpfe auf den thierischen Organismus äussern. Durch die bei gewöhnlicher Temperatur sich entwickelnden Dämpfe wurden die in einer hermetisch verschlossenen Hundshütte vorhandenen Zecken und Läuse nach 24 Stunden, während welcher Zeit 9 Grammes Benzin verdampft waren, bloss betäubt gefunclen; ein gleiches Resultat wurde bei der 
durch Wärme erzeugten Verdampfung selbst bedeutender Quantitäten Benzins (70-130 Grammes) beobachtet; wurdelı dagegen die Wände der Hütte mit Benzin bestrichen, so gingen die genannten Thiere selır raseh zu Grunde.

Die vierte Reilie von Versuchen betraf die Wirkung des Benzins in flüssiger und in Dampfform auf den Thierorganismus. Ein Sperling ging unter einer Glasglocke, unter welcher 95 Tropfen Benzin verdampft wurden; binnen 15 Minuten zu Grunde. Ein Hund wurde in einem geschlossenen, 1 Meter hohen, $1 \frac{1}{2}$ Meter langen und 70 Centimeter breiten, allenthalben luftdicht verschlossenen Raum gesperrt und in demselben von 100 Grammes 25 Grammes Benzin mittelst einer Weingeistlampe verdampft. Nach 28 Minuten wurde der Hund unruhig, hob und senkte den Kopf, drehte ihn nach rechts und links, der Blick war stier, die sichtlichen Schleimhänte erschienen geröthet, die Respiration beschleunigt, mit starker Flankenbewegung, und gleichzeitig stellte sich heftiges Zittern ein; aus dem offenstehenden Munde floss eine grosse Menge eines fadenziehenden Schleimes aus. Nachdem der beschriebene Zustand gegen zwei Minuten gedauert hatte, stellten sich krampfhafte Zusammenziehungen der Muskeln, besonders der Strecker, ein, so dass die Füsse ganz, steif gehalten wurden; der ganze Körper wurde stossweise erschüttert, das Athmen immer beschwerlicher; endlich stürzte das Thier zusammen; die Krämpfe dauerten an, das Maul erschien so weit geöffnet, dass man den Pharynx und das Gaumensegel erblickte. Die Lider waren stark geöffnet, die Pupille erweitert, der Blick wild und stier, es traten klonische Krämpfe an den Extremitäten auf, das Athmen wurde immer schwerer und der Hund schien asphyktisch werden zu wollen; aus dem Behältnisse herausgenommen daucrten die 
angeführten Symptome durch 4 Minuten an; nach und wach verloren sie an Intensität, der Ausdruck wurde weniger ängstlich, das Maul schloss sich nach und nach, und auch das Athmen wurde leichter, der Gang des Thieres war schwankend und gleichzeitig erschienen Drehbewegungen von rechts nach links; nach 8 Minuten waren auch diese Erscheinungen verschwunden und das Thier zeigte sich gesund.

Bei dem dritten und vierten Versuche wurde das Benzin zwei Hunden innerlich verabreicht. Das erste Thier erhielt 12 Grammes ( $2 \frac{3}{4}$ Drachmen). Unmittelbar nach der Verabreichung stellten sich die oben aufgezählten Erscheinungen ein und hielten durch 8 Minuten in mässiger Intensität an; dem zweiten Hunde wurden zuerst 25 Grammes eines, wie sich später erwies, unreinen Benzins verabreicht, worauf reichlicher Ausfluss eines schaumigen, klebrigen, zähen Schleimes aus dem Munde, beschleunigtes Athmen, starke Röthung der sichtbaren Schleimläute sich einstellte. Zehn Minuten nach der Beibringung des Benzins beugte das Thier die Vordergliedmaassen, verdrehte den Hals und kroch am Boden $2-3$ Schritte weit, wobei er Schnauze und Körper am Boden rieb. Nach 5 Minuten waren die Erscheinungen verschwunden.

Demselben Thiere wurden später abermals 25 Grammes verabreicht, worauf heftige Krämpfe, Unempfindlichkeit und in weniger als 2 Minuten der Tod eintraten. Bei der un. mittelbar nach dem Tode vorgenommenen Section erschienen die Schleimhäute der Nase, des Kelllkopfes, der Luftröhre und der Bronchien geröthet, die rechte Lunge in ihren hinteren Abschnitten lebhaft roth, das Gewebe weich, elastisch, in Wasser schwimmend; die gesammten Respirationsorgane stark nach Benzin riechend. Sämmtliche Ca- 
pillirgefïsse enthielten, so wie die Her⿳亠丷⿵冂len, ein dunkles, dickflüssiges Blut, die übrigen Organe verhielten sich normal.

Rey beobachtete bei einigen Pferden nach äusserlicher Anwendung des Benzins einen rienlich starken Juckreiz, der sich jedoch binnen kur'zer Zeit wieder verliert. Ebenso bestätigt er die töltende Wirkung des Benzins auf ausgebildete Insekten oder auf deren Larven, erinnert jedoch dabei an die von ilm und Anderen gemachte Erfahrung, dass dieses Mittel die Lebensfähigkeit der Eier nicht zerstöre. Was die Wirksamkeit des Benzins bei der Krätze anlangt, so wird bemerkt, dass Dr. Lambert diesen Stoff bei der Krätze des Menschen mit vollständigem Erfolge benutzte; eben solche Resultate erhielten andere Aerzte bei gleicher Behandlungsweise.

Auch als anästliesirendes Mittel wurde es von Snow und Simpson erklärt, indess wirkt es zll unsicher und zwar nicht wie das Cliloroform, sondern wie die ätherischen Oele in grossen Gaben. Auch Baschetti*) liat Versuche über die Wirkung des Benzols und des Nitro-Benzols auf den thierischen Organismus angestellt. Hiernach wirkt das Nitro-Bezol auch in geringen Dosen auf kleinere Thiere als Gift, bei dem Einathmen aber niclit anästhesirend. Das Benzol wirkte erst in grösseren Dosen (10 Grammes bei Kaninchen) tödtlich; bei dem Einathmen trat rasch Unempfindlichkeit ein, zugleich aber Krämpfe.

$\left.R e y^{* *}\right)$ vervollständigte die Versuche $R$ e y nal's über die

*) Cimento. III. 414. Jahresbericht der Chemie von J. Liebig und II. Kop p für 1856. Giessen 1857. pag. 607.

**) Recueil de medecine veterinaire. 1861. pag. 499. Oesterreichische Vierteljahresschrift für wissenschaftliche Veterinärkunde, redigirt von Prof. Dr. Müller und Prof. Dr. Roell. Jahrgang 1862. p. 150. Referent: Dr. Forster. 
Wirksamkeit des Benzins bei innerlicher Anwendung, und zwar wendete er es nicht nur bei Hunden, sondern auch bei Pferden an. Der erste Versuch wurde an einem 6jährigen Pferde gemacht, welches als rotzverdüchtig überbracht, einen einseitigen Nasenausfluss und eine harte Drüsenanschwellung im Kehlgange und nach Verlauf von 5 Tagen auch Geschwüre auf der Nasenschleimhaut zeigte. Dieses Thier wurde durch 32 Tage mit Benzin behandelt, und zwar erhielt es am 1. Tage 10, am 2. und 3. Tage 15, vom 4. bis 14. Tage 20 , vom 15 . bis 19 . Tage 50 , am 20. Tage 100 , vom 21. bis 27 . Tage 150 , vom 28. bis 32. Tage 100 Grammes täglich in Honigwasser; es hatte somit im

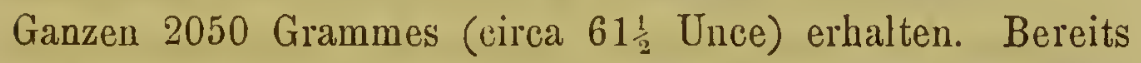
nach den ersten zwei Gaben trat eine bedeutende Verstopfung ein, die trotz der Anwendung von Klystieren 7 bis 8 Tage anhielt, später jedoch trotz der gesteigerten Gabe uicht an Hartnäckigkeit zunahm; die Kothballen waren hart, mit einer braunen, glänzenden Schleimhaut überzogen. Die ausgeathmete Luft roch schon nach $3-4$ Tagen äusserst stark nach Benzin; die Fresslust dauerte bis zur Verabreichung einer Gabe von 150 Grammes an, stellte sich aber bei Verminderung der Dosis auf 100 Grammes wieder ein. Der Ernährungszustand besserte sich auffallend, und als das Thier 5 Tage nach Verabreichung der letzten Gabe getödtet worden war, fand sich eine dicke Schicht eines blassgelben Fettes an der Bauchwandung, um die Nieren, zwischen den Gekrösplatten und überall, wo überhaupt Fettablagerungen vorkommen. Der Verdauungstrakt zeigte sich durchaus normal. An der Nasenschleimhaut fanden sich neben zwei verheilten viele frische Rotzgeschwüre, die Nebenhöllen der Nase enthielten eine jauchige Flüssigkeit 
in nicht geringer Menge, an den Knochen daselbst zeigten sich Osteophyten. An beiden Lungen bemerkte man zahlreiche kleine Abscesse.

Der zweite Versuch wurde an einem siebenjälırigen, mit chronischem Rotze behafteten Cavalleriepferde angestellt. Dasselbe erhielt durch 15 Tage täglich cine Gabe von 10 Grammes Benzin in mit Honig versüsstem Wasser, ohne dass irgend eine besondere Erscheinung, eine Verzögerung des Mistabsatzes abgerechnet, eingetreten wäre; auf die durch zwei Tage verabreichte Gabe von 50 Grammes Benzin wurde das Thier traurig und verlor die Fresslust; die ansgeathmete Luft roch stark nach Benzin, entzündete sich bei Annäherung eines breunenden Gegenstandes nicht. Auch bei der Section des vertilgten Thieres fand man reichliches Fett abgelagert.

Auch das dritte Versuchspferd, eine achtjährige Stute, wurde wegen chronischen Rotzes überbracht. Dieselbe bekam um 11 Uhr Vormittags 500 Grammes (gegen 28 $\frac{1}{2}$ Loth) Benzin mit $1 \frac{1}{2}$ Maass Wasser gemengt. Nach 20 Minuten zeigte sich ein auf $60 \mathrm{Schläge}$ beschleunigter Puls, ein Atllmen auf 42 Züge; der Kopf wurde gesenkt gelialten, der Blick war stumm, die Extremitäten fühlten sich kühl an; eine Stunde später ging normal gefürbter Mist und dunkelgefärbter Harn ab; weiterhiı hob sich der Puls auf 70 Schläge, das Athmen auf 54 Züge, und gleichzeitig liess die ausgeathmete Luft das Benzin deutlich erkennen. Um 7 Uhr Abends war der Puls auf 50, das Athmen auf 26 gesunken, und am nächsten Morgen zeigten sich keine Nachwirkungen des Medikamentes, nur hatte die ausgeatlmete Luft noch immer den obenerwähnten Geruch, der sich noch am nächsten Tage bemerkbar machte. Vicr Tage nach der Verabreichung der ersten Gabe wurden dem Thiere 
750 Grammes in der obenerwähnten Form beigebracht. Um 1 Uhr war der Puls auf 80 Schläge, das Athmen auf 60 Züge gestiegen, das Thier war selır matt, stützte sich auf die Krippe, im Gange schwankte es stark, und drohte bei jedem Schritte zu stürzen; die ausgeathmete Luft war kühl und roch stark nach Benzin; Abends war Verstopfung zugegen, dagegen ging Harn in reichlicher Menge ab. Die Pulsbeschleunigung war auch noch am dritten Tage nach dem Versuche zugegen, das Thier verschmähte Futter und Getränlie, die Maulspalte konnte nicht ohne Gewalt geöffnet werden.

Am 4. und 5. Tage war der Herzschlag unfühlbar, der Puls sehr klein, das Athmen röchelnd, die Schleimhäute erschienen sehr blass und kühl; das sehr schwache Thier war äusserst unaufmerksam; am nächsten Morgen ging es unter Convulsionen ein. Bei der Section fand sich an den Rotzgeschwüren keine Aenderung; die Schleimhaut der Maul- und Rachenhöhle war normal, jene des Schlundes war bleich und mit grünlichen Flecken besetzt, welche sich auch im Magen vorfanden; die Schleimhaut des Zwölffingerund des Leerdarmes zeigte sich, sowie jene des Dickdarnes, bleifarben; in dem Darme selbst fanden sich nur wenig Futterreste. Lungen und Bronchien waren unverändert.

Bei einem 10 Monate alten, grossen Hunde trat unmittelbar nach der Verabreichung von 100 Grammes Benzin heftige Aufregung, Frostschauder, sehr beschleunigter Puls, eben solches Athmen, Schäumen aus dem Munde, Aneinanderschlagen der Kiefer, stierer Blick, erweiterte Pupille, erschwerter Gang, wiederholtes Niederstürzen, Drehen im Kreise und Betäubung ein. Diese Erscheinungen dauerten etwa 20 Minuten an und verschwanden bis aut 
eine Schwäche der Gliedmaassen; der Koth wurde durch 3 bis 4 Tage nicht abgesetzt, und eben so roch die ausgeathmete Luft stark mach Benzin. Binnen 5 Tagen hatte der Hund seine Gesundheit wieder erlangt.

Auch bei chronischem Magen- und Darmkatarrhe, gegen Bremsenlarven und gegen Eingeweidewürmer versuchte Rey das Benzin. Bei der erstgenannten Krankheit will er nach mehrtägiger Verabreichung von je 100 Grammes eine auffallende Besserung der Fresslust und des Nährzustandes in mehreren Fällen beobachtet haben, und hält das in Rede stehende Mittel auch zur Entfernung der Bremsenlarven für wirksam, da er bei den Thieren, denen er dasselbe verabreichte, die Larven mit dem Miste abgehen sah, ebenso will er durcl das Benzin in der Gabe von 100-200 Grammes günstige Erfolge bei Eingeweidewürmern erzielt haben. Nach einer Gabe von 100 Grammes gingen bei einem Pferde gegen 80 Spulwürmer verschiedener Grösse, die sämmtlich todt waren, ab; bei einem Hunde trieb er durch zwei Gaben von 40-60 Grammes zahlreiche Exemplare von Taenia serrata ab und erhielt auch in einem zweiten Falle ein gleiches Resultat. Er spricht sich schliesslich dahin aus, dass auch bei Menschen das Benzin als ein wurmtreibendes Mittel zu versuchen wäre, wenn es gelingen würde, den üblen Geruch und Geschmack durch irgend einen Stoff zu decken.

So viel glaubte ich über die Eigenschaften des Benzius aus der vorhandenen Literatur erwähnen zu müssen, um zu begründen, warum ich vor allen anderen Mitteln nach der Pikrinsäure die anthelminthische Wirkung des Benzins gegen Trichiniasis und Finnenkrankheit geprüft habe. Um mich mit der Art und Weise seiner Wirkung auf die inneren Organe, der 
Grösse der anzuwendenden Dosen etwas genauer bekannt zu machen, habe ich Vorversuche bei Kaninchen angestellt, die nicht trichinisirt waren. Das mir von Herrn Professor Mettenheimer gelieferte Benzin wurde mit Eidotter in Emulsion verarbeitet, und durch einen elastischen Katheter direkt in den Magen injicirt.

1) Einem starken ausgewachsenen Kaninchen wurden am 19. August Abends 5 Uhr 10 Gran Benzin in Eiemulsion in den Magen injicirt, am 20. August 20 Gran; am 21. August ebenfalls 20 Gran und am 22. August 30 Gran, ohne dass gefährliche Symptome eintraten. Es wurde das Mittel nunmehr ausgesetzt, und auch an den folgenden Tagen zeigte sich keine Nachwirkung von den 80 Gran Benzin.

2) Einem anderen Kaninchen wurden am 19. August Morgens 11 Uhr und Nachmittags 5 Uhr je 5 Gran Benzin, und am 20. August Mittags 12 Uhr auf ein Mal 10 Gran Benzin injicirt in den Magen; unmittelbar darnach stellte sich, eben so wie auch bei dem vorhin erwähnten Kaninchen, bedeutende Aufregung, Zittern, Pulsbeschleunigung, gesteigerte Athemfrequenz ein, wovon sich die Thiere bis zum Abend wieder vollständig erholt hatten.

Am 21. August erhielt das Thier 15 Gran Benzin, am 22. August Morgens 10 Uhr 20 Gran, und Mittags 3 Uhr 40 Gran Benzin. Es wiederholten sich die oben erwähnten Erscheinungen in sehr stürmischer Weise.

Am 23. August Morgens 11 Uhr erhielt das Thier auf ein Mal 1 Drachme Benzin in den Magen. Unmittelbar nachher fiel es in einen der Ohnmacht ähnlichen Zustand, der Herzschlag ging fort, das Athmen wurde nicht wahrgenommen. An die frische Luft gebracht erholte es sich nacl 5 Minuten wieder. Zittern und Aufregung des Gefäss- 
systemes dauerten lang an; auch bemerkten wir eine Parese der hinteren Extremitäten, so wie eine über den ganzen Körper verbreitete Anästhesie. Man konnte das Thier auf die Vorder- oder Hinterbeine heftig drücken, sie wurden nicht zurückgezogen; es reagirte nicht auf festes Kneipen der Haut an irgend einer Stelle des Körpers, und blieb selbst ganz ruhig, als es an den Barthaaren heftig gezerrt wurde. Am Abend hatte sich das Thier mehr erholt.

Am 24. August Morgens $10 \mathrm{Uhr}$ wurde ihm abermals 1 Drachme Benzin in Emulsion auf ein Mal vorsichtig in den Magen durch einen Katheter injicirt. Schon während der Operation zeigte es lebhafte Convulsionen; auf den Boden gelegt traten die lebhaftesten tetanischen Zuckungen ein; es folgten mehrere sehr helle Schreie und darnach Tor.

Die bald darnach vorgenommene Autopsie ergab Folgendes:

Beim Durchschneiden der Bauchhaut fiel die sehr beträchtliche Quantität in den Milchdrüsen angesammelter Milch auf, welche übermässige Milchsecretion möglicherweise Effekt des Benzins war, da das Thier gegenwärtig nicht trächtig war. Sämmtliche Muskeln hatten ein verändertes Aussehen, mehr gelbliche Färbung, Geruch nach Benzin. Die Venen meist stark angefültt. Die Lungen, besonders die rechte, auffallend blutreich, in den hinteren unteren Partieen etwas verdichtet. Im Mediastinum anticum ein massiges fibrinoses Exsudat, das der äusseren Oberfläche des Herzbeutels auflag; im Pericardialcavum ein ähnliches, das eine ansgedehnte Verklebung des visceralen und parietalen Blattes bedingt hatte. Her'zmuskulatur blutreich. Endocardium und Klappen normal. Herzlöhlen beiderseits mit massenhaften Gerinnseln erfüllt, die sich besonders in die Lungen fortsetzten. Magen und Darmkanal zeigten auf 
ihrer Schleimhaut an vielen Stellen Zeichen mässigen Katarrhes, wareu reichlich mit Futtermassen erfüllt.

Die Leber blutreich, vergrössert, zeigte auf ihrer Oberfläche zahlreich zerstrente, stecknadelkopf - bis linsengrosse Punkte, die sich unter dem Mikroskope als Fettleber erweisen. Nieren gross, blutreich. Gehirn und Rückenmark wurden dieses Mal nicht untersucht.

Aus diesem Versuche konnte entnommen werden, dass 1 Dr. Benzin diejenige Gabe ist, welche bei einem Kaninchen den Tod herbeiführt.

3) Einem alten Kaninchen, das am 3. Juli mit ausserordentlich dicht mit Trichinen durchsetztem Kaninchenfleische gefüttert war, wurde vom 19. August an, also 7 Wochen nach der Fütterung, in der oben erwähnten Weise Benzinemulsion in den Magen gespritzt, um den Einfluss desselben auf die Muskeltrichinen zu erfahren.

Die Gaben des Benzins waren folgende:

$$
\begin{aligned}
& \text { am 19. August }=5 \text { Gran Benzin, } \\
& \text { "20. } \quad=10 \% \text { " } \\
& \text { "21. } \quad=20 \% \text { " } \\
& \text { "22. \# Mergens } 10 \mathrm{Uhr}=20 \mathrm{Gran} \text {, Mit- }
\end{aligned}
$$

tags 3 Uhr $=40$ Gran.

22. August. Heute fiel mir eine sehr bedeutende Abmagerung des Thieres, Lähmung der hinteren Extremitäten auf. Morgens 11 Uhr wurde 1 Dr. Benzin auf 1 Mal in den Magen gespritzt. Unmittelbar darnach traten heftige tetanische Krämpfe ein; das Thier that einen lauten Sclırei, wir glaubten, sein Ende sei da, als es darnach zu Boden fiel. Es erholte sich wieder, begann lebhaft zu zittern, sass die nächste Viertelstunde in sehr aufgeregtem Zustande mit rascher Puls- und Athemfrequenz an derselben Stelle am Boden. Auffällig war auch hier Anästhesie über den gan- 
zen Körper, die wir gewahrten, als wir wiederholt den Versuch machten, durch Aufklopfen anf die Beine, oder durch Kneifen der Haut an anderen Stellen tetanische Zuckungen liervorzurufen. Es wurden dabei weder die Vorder-, noch die Hinterbeine zurückgezogen, es reagirte an keiner Hautstelle auf das Kneifen, blieb selbst ganz ruhig, als ich es an den Barthaaren kräftig zerrte. Wiewohl sich das Thier am Nachmittage wieder mehr erholt hatte, war doch noch Aufregung des Gefässsystemes, Parese der hinteren Extremitäten und Empfindungslähmung geblieben.

Am 24. Angust wurde dem Thiere noch $\frac{1}{2}$ Drachme Benzin in den Magen gespritzt. Es war darnach anfangs wie betäubt, that einzelne sehr helle Schreie, denen eine Minute lang tetanische Zuckungen folgten; es erholte sich wieder, zeigte in der Folge noch Zittern, Parese der hinteren Extremitäten, Empfindungslähmung.

Um 12 Uhr wurde das Thier getödtet, um die Wirkung zu constatiren, welche die innerhalb 5 Tage gegebenen 3 Drachmen Benzin auf die Muskeltrichinen gehabt.

Bei genauer Untersuchung der Muskeln zeigten die zum Theil schon in der Einkapselung begriffenen, ausgewachsenen Muskeltrichinen ganz normales Verhalten; bei vielen konnten durch Erwärmen des Objektträgers über einer Spiritusflamme noch Bewegungen erzielt werden, die indess nicht so lebhaft und andauernd waren, als ich sie bei anderen Thieren, die nicht mit Benzin behandelt waren, gesehen habe. Die Muskeln zeigten eine durch das Benzin herbeigeführte, eigenthümliche Veränderung in Farbe und Aussehen.

Um mich weiter zu überzeugen, ob die Trichinen des mit Bezin behandelten Kaninchens wirklich noch lebens- 
fahig seien, habe ich noclı am 24. August von demselben Fleische drei Kaninchen gefüttert. Eins davon starb bereits am 28. August, und fand ich bei der Autopsie im Dünndarme zahreiche geschlechtsreife Darmtrichinen in lebhafter Bewegung; von den anderen Kaninchen habe ich eins am 18. September untersucht, und lebende Muskeltrichinen angetroffen.

4) Um die Einwirkung des Benzius auf die Darmtrichinen zu studiren, wurden einem ausgewachsenen Kaninchen, das am 24. und 25. August mit einer grossen Portion trichinisirten Muskelfleisches gefüttert worden war, am

26. August 30 Gran Benzin in Emulsion in den Magen injicirt,

.27. August Morgens $9 \mathrm{Uhr}=30 \mathrm{Gran}$, Nachmittags $5 \mathrm{Uhr}=30$ Gran,

28. August Morgens $10 \mathrm{Uhr}=30 \mathrm{Gran}$.

Das Thier war darnach sehr angegriffen, hatte vorübergehend Zuckungen, war an den hinteren Extremitäten gelähmt. An den folgenden Tagen erholte es sich wieder. Am 5. September (12 Tage nach der Fütterung) wurde es todt im Stalle gefunden.

Im Darmkanal, dessen Schleimhaut sehr deutliche Zeichen von Enteritis darbot, fand sich eine grosse Zahl von Darmtrichinen, die sämmtlich abgestorben waren; selbst beim Erwärmen des Objektträgers war unter dem Mikroskope keine Bewegung mehr an ihnen wahrzunehmen.

Um diese Zeit erhielt ich durch Herrn Professor Dr. Mettenheimer ein aus der Merk schen Fabrik bezogenes reineres Benzin, das ich nunmehr zu meinen Versuchen benutzte. Seine grössere Wirksamkeit liess sich schon daraus ableiten, dass die Muskeltrichinen, welche mitsammt 
dem Fleische in dieses reinere Benzin gelegt wurden, schon nael $3-5$ Stunden sïmmtlich abgestorben waren, während es bei dem frïheren seclis und inchr Stunden gedauert hatte. Auch vertrugen die Kaninclıen dasselbe nicht in so grosser Gabe, wenn es innerlicl gegeben wurde, wie das frïlere. Ich hatte den raschen Tod von zwei trichinisirten Kaninchen zu beklagen, denen ich zwei Tage hintereinander nur 1 Scr. Benzin in Eidotteremulsion durch einen Katheter in den Magen eingespritzt hatte. Die oben erwähnten Intoxicationssymptome waren alsdann noch viel auffallender:

5) Um dieses Benzin in grossen Gaben gegen Trichiniasis versuchen zu können, habe ich es bei einem etwa vier Monate alten Schweine angewandt. Demselben walen folgende Helminthen gefüttert worden:

a) am 21. August 1863 cine Anzahl von Proglottiden der Taenia solium; in den Eiern habe ich 6hakige Embryonen aufgefunden; gross war indess die Zahl der reifen Proglottiden nicht;

b) am 29. August einen Kaninchendarm mit einer grossen Zahl von lebenden Darmtrichinen;

c) am 3. September abermals einen Darm mit Darmtrichinen, und gleichzeitig eine grosse Portion trichinigen Muskelfleisches;

d) am 28. September nochmals eine grosse Portion trichinigen Muskelfleisches.

Mit der Darreichung des Benzins war begonnen am 22. September $-\frac{1}{2}$ Drachme mit Wasser velmischt,

23.

24.

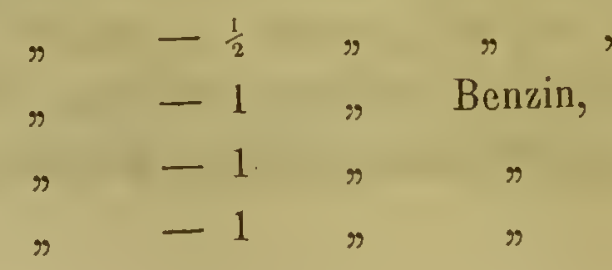

25.

26. 
27. September - 1 Drachme Benzin,

28. $\quad-1$ "

30. $\gg-1, \pi$ ind so fort bis zum 6. Oktober, zu welcher Zeit die gereichte Menge im Ganzen 12 Draclımen $=1 \frac{1}{2}$ Uncen Benzin betrug.

Das Thier war seit der Fütterung mit Trichinen sehr abgemagert, hatte struppige Haare, matten Blick, heisere Stimme, frass aber noch mit derselben Gier wie früher.

Da es vom Benzin angegriffen wurde, habe ich das Mittel rom 6. bis 10. Oktober ganz ausgesetzt, und am 10., 11., 12., 13., 14. Oktober nur $\frac{1}{2}$ Drachme im Tage

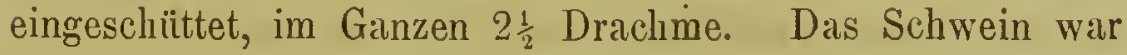
nunmehr ganz hinfällig, an den hinteren Extremitäten laalb gelähmt, aphonisch, traurig. Es erhielt weiter am

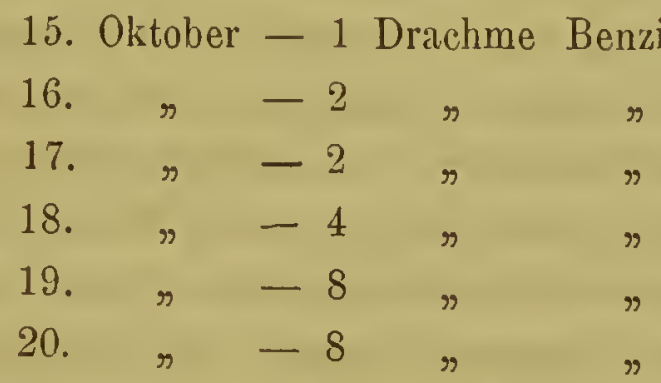

Tod am 20. Oktober unmittelbar nach der letzten Gabe Benzin.

Im Ganzen waren etwas mehr als 5 Uncen Benzin gegeben worden vom 22. September bis 20. Oktober.

Sektion am 21. Oktober Morgens 9 Uhr.

Leiche stark abgemagert, Unterhautzellgewebe fast ganz fettlos, Muskeln von normalem Anssehen, etwas blass, Muskelstarre in mässigem Grade vorhanden.

Eröffnung des Schädels: Aeussere Decken blass, die Gehirnhäute zeigten erweiterte, stark angefüllte Venen; Gehirn selbst von normalem Blutreichthum, normaler Fürrbung, 
Consistenz etwas weicher, als gewöhnlich. Finnen waren nicht darin nachweisbar.

Die Venen der Rückenmarkshäute stark erweitert, blutreich, das Mark selbst von weicher Consistenz. Auffallender Benzingeruch daran nicht erkennbar. Die Venen am Halse stark angefüllt. Lymphdrüsen daselbst angeschwollen. Kehlkopfschleimhant geröthet, die Muskeln stark geröthet, geschwellt, enthielten sehr zahlreiche Muskeltrichinen, die Schleimhaut der Trachea in ihren oberen Partieen weniger geröthet, um so mehr in der Nähe der Bifurkation und von da nach abwärts, mit reichlichem, schaumigem, blutig-eitrig-serösem Sekrete angefüllt. Die linke Lunge in ihrem unteren Lappen völlig hepatisirt, der obere Lappen zeigte weit vorgeschrittenen Katarrh. Die rechte Lunge durch derbe Adhäsionen zwischen Pleura pulmonalis und costalis der Thoraxwand angeheftet, der untere Lappen zeigte frische Hepatisation, der mittlere fühlte sich von aussen selı derb, schwielig an, beim Einschneiden quoll aus dem in seiner Mitte befindlichen Abscesse eine dicke, schmutzig grüne Eitermasse heraus; die Umgebungen des Abscesses sehr verdickt, schwielig, woraus zu entnehmen, dass diese Veränderung schon länger bestand. Lymphdrüsen an der Lungenwurzel stark geschwellt.

Herzbeutel hyperämisch sowohl im Parietal-, wie in dem Visceralblatte, enthielt reichliche Menge trüben Serums; an dem Ursprung der Gefässe blutig seröse Schwellung. Herzfleisch dunkel. Klappen des linken Ventrikels an ihrer Basis sehr blutreich, verdickt; im rechten Ventrikel lockere Gerinnsel. Schlund wenig geröthet, Magen mit Speiseresten erfüllt, Schleimhaut in ganzen Fetzen abgestossen, Epithel erweicht. Darm zeigte an vielen Stellen deutliche Zeichen von Katarrh der Schleimhaut, mit flüssi- 
gem Inhalte erfüllt. Peritoneum geröthet, Lymphdrüsen stark geschwellt. Leber, Milz, Nieren normal. Im Darm fanden sich noch einzelne Darmtrichinen, die insgesammt bewegungslos, auch durch Erwärmen nicht lebendig gemacht werden konnten.

Die Muskeln waren ganz massenhaft mit Trichinen übersät, und zwar liessen sich an ihren Entwicklungsstadien die verschiedenen Fütterungstermine erkennen. Indem ich das trichinige Muskelfleisch nicht blos zur Zeit der Anwendung des Benzines, sondern lange Zeit vor der Darreichung des Benzines gefüttert, war in diesem Falle schwer zu entscheiden, ob das Benzin auf die Entwicklung der Darmtrichinell, und die Einwanderung der Embryonen einen Einfluss gehabt; möglicherweise war ein Theil der Darmtrichinen durch das Benzin untergegangen. Ob auf die Muskeltrichinen die von uns angewandten 5 Uncen Benzin einen Einfluss gehabt, liess sich bestimmter entscheiden. Bei der mikroskopischen Untersuchung kounte ich Bewegungen der Muskeltrichinen, selbst nach Erwärmen des Objektträgers, nicht wahrnehmen, es war auch der Inlalt der Trichinen, so wie ihre Kapsel bei vielen von mir untersuchten Exemplaren etwas getrübt, granulirt. Da ich aus dieser Beobachtung noch keine sichere Schlüsse zu ziehen wagte, habe ich von diesem Muskelfleische am 23. Oktober eine grosse Portion an ein Kaninchen gefüttert; dasselbe war am 30. Oktober gestorben. Bei der am 31. Oktober von mir vorgenommenen Sektion fand ich im Darme nur sehr wenige Darmtrichinen, welche überdies nicht die lebhaften Bewegungen zeigten, die man sonst bei Darmtrichinen wahrnimmt. Ich habe verschiedene mikroskopische Präparate vom Darminhalte dieses Kaninchens durchsuchen müssen, ehe ich nur eine Darmtrichine auf- 
fand. Es war mir darnach nicht unwahrscheinlich, dass die bei unserem Schweine angewandten 5 Uncen Benzin auf einen Theil der Muskeltrichinen einen deletären Einfluss geäussert.

Finnen, welche von der am 21. August stattgeliabten Fütterung mit Taenia solium stammen konnten, habe ich weder in den parenchymatösen Organen, noch in den Muskeln auffinden können. Dieses negative Resultat darf indess nicht mit der Darreichung des Benzins in Verbindung gebracht werden, da ich vielfach in Folge unbekannter individueller Verhältnisse auch bei anderen Schweinen, die nicht mit Benzin behandelt worden waren, die Embryonen der Taenia solium nicht zur Entwicklung von Finnen kommen sah, überdies in unserem Falle, da das Benzin erst vier Wochen nach der Fütterung mit Taenia solium angewandt worden war, doch Spuren der durch Benzin zu Grunde gegangenen Finnen hätten nachweisbar sein müssen.

6) Einem fünf Monate alten Rinde wurden

am 25. August 1863 etwa 150 Grammes stark trichinigen Kaninchenfleisches gefüttert,

am 28. September wiederum 120 Grammes,

am 6. Oktober nochmals 100 Grammes,

am 13. Oktober abermals 150 Grammes,

am 22. Oktober 400 Grammes Schweinefleisch, das massenhaft mit Trichinen inficirt war,

am 24. Oktober nochmals 300 Grammes von demselben Schweinefleisch.

Ferner waren dem Thiere am 6. Oktober Mittags 5 Uhr 100 reife, und noch eine grosse Zahl nicht ganz reifer Proglottiden der Taenia mediocanellata gefüttert worden. Bereits am folgenden Tage, dem 7. Oktober, habo ich mit der Darreichung des Benzines begounen, und zwal wurden 
am 7., 8., 9., 10. und 11. Oktober an jedem Tage je

$1 \frac{1}{2}$ Drachme gegeben, welche das Thier ohne jede Beschwerde vertrug; unmittelbar nachher hustete es öfters,

am 12., 13., 14., 15. und 16. Oktober erhielt es täglich

$\frac{1}{2}$ Unce Benzin,

am 18. Oktober 1 Unce Benzin,

am 19. Oktober 2 Uncen Benzin,

am 20. Oktober 1 Unce Benzin,

am 22. Oktober 1 Unce unmittelbar nach Fütterung des

Schweinefleisches,

am 24. Oktober 1 Unce desgl.

Es waren im Ganzen $9 \frac{1}{2}$ Uncen Benzin gegeben worden. Ausser Abmagerung und Schwäche der hinteren Extremitäten, Auftreibung des Banches waren an dem Thiere keine Krankheitserscheinungen wahrzunehmen.

Besondere Umstände nöthigten mich dazu, jetat schon (am 22. Tage nach der Fütternng mit Taenia mediocanellata) den Versuch zu unterbrechen.

Um indess das Thier für das Benzin noch zu verwerthen, benutzte ich die Gelegenheit zur Entscheidung der Frage, wie viel von dem Benzin zur Tödtung dieses über $\frac{1}{2}$ Jahr alten Rindes erfordert würden. Am 28. Oktober Nachmittags 3 Uhr wurden demselben 4 Uncen Benzin, in etwas Wasser suspendirt, eingegossen. Es wurde alsbald darnach zitterig, schwach auf den Beinen; die Respiration ward sehr beschleunigt, schnaufend; über den ganzen Körper verbreitete sich Hitze, die Augen wurden glänzend, der Bauch war sehr rasch aufgedrungen. Nach 3 Minuten fiel es, nachdem es vorher wio schwindelig mit dem Kopfe geschaukelt, auf den Boden, zitterte mit den Hinterbeineu, streckte dieselben mitunter sehr rasch aus, zog sie dann 
wieder zusammen. Für Berührung waren dieselben unempfindlich, mehr als die Vorderfüsse. Das Thier war sehr unruhig; die Athemfiequenz, die Pulsfrequenz und die Hitze hatten noch zugenommen. Mit einem Male sprang es wieder auf, und konnte mit einiger Unterstützung stehen. Als wir es alsdann an die Luft fülurten, erholte es sich rasch wieder; der Bauch fiel wieder mehr bei, das Athmen war ruhiger, das Gehen leichter.

Um den raschen Tod des Thieres herbeizuführen, liess ich ihm nochmals 2 Uncen Benzin eingiessen, wonach die Respiration wieder schr frequent wurde, der Bauch sich von Neuem auftrieb, und das Thier zu Boden fiel. Es zeigte einige Zuckungen am Körper, streckte mit einem Male die Beine aus, schloss die Augen, und war schon nach 2 Minuten todt.

Bezüglich der toxischen Wirkung des Benzins hat dieser Versuch ergeben, dass die Gabe von 4 Uncen Benzin bei einem $\frac{1}{2}$ jährigen Rinde den Tod noch nicht augenblicklich herbeiführt. Nach früheren Versuchen an Kaninchen und Schweinen, die ähnliche Zufälle, selbst in bedeutenderem Grade nach grösseren Galıen von Benzin gehabt, und sich wieder vollständig erholt hatten, glaube ich anmehmen zu müssen, dass auch diese 4 Uncen Benzin von dem Thiere vertragen worden wären, zumal ihm früher schon 2 Uncen auf einmal gegeben worden waren, ohne dass wahrnehmbare Zufälle darnach eintraten. Als dagegen die Wirkung von zwei neuen Uncen Benzin hinzugekommen war, starb das Thier sofort, so dass demnach 6 Uncen Benzin als diejenige Gabe zu betrachten sind, nach welcher der Tod bei einem Rinde dieses Alters sicher eintritt. Die Nervenerscheinungen waren nicht so ausgebildet, wie bei 
den Kaninchen, vielmehr traten hier die Erselıeinungen von Seiten der Respirationsorgane in den Vordergrund, wesshalb wohl jene von letzteren abzuleiten sind, wofür auch die bei der Section gewonnenen Resultate sprachen.

Die Seetion wurde am 29. Oktober vorgenommen.

Muskelstarre in geringem Grade vorhanden. Abmagerung fellte; bedeutende Fettmasse im Unterhautzellgewebe abgelagert. Bauch aufgetrieben. Beim Einsehneiden der Hiut verbreitete sich starker Gerueh nach Benzin. Die Muskeln etwas blass. Beim Präpariren derselben fand man darin abgelagerte Finnen, die indess im Vergleiel zu meiner frïheren Section beim Rinde sparsam waren, die meisten in den Bauch - und Brustmuskeln, sehr wenige in denen des Halses und der Extremitäten. Die Mehrzahl derselben hatte ein ganz eigenthümliches Aussehen, sie waren mehr als erbsengross, gelblich, mit sehr derber Kapsel; beim Einschneiden quoll eine gelbe, dickliehe Masse heraus, die aus Fett und Bindegewebskörperehen bestand; in den meisten war der Cysticereus untergegangen, etwa in dem Verhältnisse, dass in seehs so aufgeschnittenen Cysten nur ein Mal ein Cystieercusbläschen aufgefunden wurde. Das Stadium der Entwicklung der Finnen war ganz dasselbe, wie ich es in meinem ersten Falle beschrieben habe. Solche Finnen, die sich schon beim blossen Ansehen als wohlerhalten erwiesen, fand ielı in den Muskeln des Bauches sehr wenige, etwas zahlreicher in dem Zwerehfelle und dem Herzen. In dem Zwerchfell waren sie wieder etwas länglich gezogen. Das Herz war vergrössert, an seiner Oberfläehe, insbesondere auf dem linken Ventrikel, viele weisse Knötchen von Hirsekorn-bis Linsengrösse, welche ebenso wie all dem bereits beschriebenen Herzen Tuberkeln gleiehen; daneben fanden sieh zahlreielıe erbsengrosse Kno- 
ten von melır gelblichem Aussehen, deren Eigenthümlichkeit ich so eben beschrieben habe. Circumferenz des Herzens am Ursprung der Gefässe $=29 \mathrm{Cm}$., vom Ursprung der Aorta bis zur Spitze des linken Ventrikels $=15 \mathrm{Cm}$. Linker Ventrikel mit massigen, dunkel schwarzen Coagulis erfüllt. Wandıng des linken Véntrikels $=3 \mathrm{Cm}$. dick, die Muskelmasse roth, glänzend, von selır zahlreichen weissen Knötchen, den Anfangsstadien der Finnen, durchsetzt. Auf dem Endocardium ebenfalls zahlreiche Finnen bemerkbar, auch auf dem grösseren Zipfel der Bicuspidalklappe zwei deutliche Finnen zu sehen. Rechtes Herz gleichfalls von dunkelschwarzen Gerinnungen erfüllt; seine Wandungen $\frac{1}{2} \mathrm{Cm}$. dick, mit zahlreichen Finnen durchsetzt; es ragten dieselben auch auf dem Endocardium durch. In den Vorhöfen fanden sich weniger Finnen. Im Mediastinum anticum, besonders in der oberen Partie, ganze Stränge rosenkranzartig aneinander gereihter, stark intumescirter Lymphdrüsen; in den hinteren Partieen manche von Tauben- bis Hühnereigrösse, besonders unmittelbar unter dem Arcus aortae.

Lungen überall lnfthaltig, in der rechten unmittelbar unter der Pleura wenige Finnen abgelagert; im Innern fanden sich keine mehr. Beide Lungen sehr blutreich, die Bronchien mit schaumigem Sekrete, die Lungengefässe von dunkelschwarzen Coagulis erfüllt.

Die Zunge zeigte dieses Mal nur wenige Finnen; in dem Oesophagus fehlten sie. Schleimhaut des letzteren, sowie des Pansen, des Netzes und Blättermagens von blassem Aussehen, erweicht, an vielen Stellen ganz abgelöst, an anperen sehr leicht mit dem Finger abschabbar; selbst dic Muskulatur des Magens elweicht, sehr leicht trennbar. Der Mageninhalt verbreitete intensiven Benzingeruch, Darm- 
inhalt Alüsig; alle Versuche, welche ich gemeinschaftlich mit Herrn Professor Leuckart und Herrn Conservator Zinser anstellte, Darmtrichinen darin aufzufinden, waren fruchtlos; wie bereits an einer anderen Stelle hervorgehoben, enthielten auch die Muskeln des Thieres keine Trichinen. Die Schleimhaut des Darmkanals zeigte nichts Besonderes. Im Mesenterium waren dieses Mal gar lieine Finnen abgelagert, insbesondere war auch die Nierenkapsel ganz frei davon. Die Mesenterialdrïisen in bedeutendem Maasse angeschwollen.

Leber, Milz und Nieren zeigten nichts Auffallendes. Das Gehirn und Rückenmark normal.

Schliesslich muss noch erwähnt werden, dass die Lei che einen sehr unangenehmen Geruch verbreitete, der wohl durch das Benzin herbeigefülnt worden war; es schienen die Organe dadurch viel schueller der Fäuhniss zu unterliegen.

Was die anthelminthische Wirkung des Benzins an* langt, so hat diese Section löclist überraschende Resultate geliefert, welche der Beachtung in weiteren Kreisen werth erscheinen dürften; ich erwälne dieselben um so lieber, da auch Herr Professor Leuckart, den ich die Sectionsbefunde controliren liess, hiernach der Ansicht ist, dass das Benzin unter den anthelminthischen Mitteln eine bedeutende Stelle einnelimen wird.

Zunächst liegt es sehr nahe, bei unserem Rinde das sparsame Vorkommen der Finnen, insbesondere auch die Entartung der vielen bereits in der Entwicklung begriffeneı Finnen zum grossen Theile von der Wirkung des Benzins abzuleiten, zumal dasselbe unmittelbar nach der Fütterung mit Taenia mediocanellatil dem Thiere in grossen Gaben eingegeben worden war, sich uberdies unter den 
gegebenen Verhältnissen kein anderer Grund für diese $\mathrm{Ab}$ weichung auffinden liess. Wenn sich diese Ansicht bei ferneren Versuchen bestatigen wird, so ist das Benzin als ein Anthelminthikunı anzusehen, das nicht allein die auf der Wanderung begriffenen Embryonen der Taenia mediocanellata zu vernichten, sondern auch die Entartung der bereits entwickelten Finnen herbeizuführen verspricht.

Dass die Muskeln des Rindes keine Trichinen enthielten, llängt, wie bereits oben genauer auseinandergesetzt wurde, von der Eigentliimlichkeit des Rindfleisches ab; es scheinen die Trichinen hier nicht den für ihre Entwicklung, resp. Einwanderung günstigen Boden vorzufinden, und darf dieses negative Resultat nicht dem Benzine zugeschrieben werden.

Eine andere Sache ist die gänzliche Abwesenleeit der Darmtrichinen bei diesem Rinde. $\mathrm{Da}$ in dem früheren Falle von Professor Leuckart die Darmtrichinen so massenhaft entwickelt waren, dass das Kalb an Enteritis trichinosa zu Grunde ging, glaubten wir, in dem vorliegenden Falle annehmen zu dürfen, dass die Darmtrichinen durch das Benzin getödtet und mit dem Kothe rasch nach aussen entfernt worden sind.

7) Um diese Entdeckung entsprechend verwerthen zu können, war es von grösstem Interesse, zu erfahren, ob und in welchen Gaben das bis jetzt nur bei Thieren angewandte Benzin von Menschen vertragen werden könne. Ich wählte zu diesen Versuchen einen hiesigen Arbeiter, G. L., 37 Jahre alt, der an einem chronischen Bronchialkatarrh leidet.

Letzterer Umstand schien mir darum wichtig, weil an einer Verschlimmerung des Katarrlies sehr rasch eime nachtheilige Wirkung des Benzins auf die Respirationsorgane 
erkannt werden konnte. Wegen des sehr unangenehmen Geschmacks wällte ich die Verabreichung des Benzins in capsules gelatineuses.

Am 22. September wurden jenem Manne 10 Tropfen Benzin gegeben; unmittelbar daruach verspürte er Aufstossen und etwas Schwindel, dagegen keine Beklemmung der Brust.

Am 23. September Morgens erhielt er 15 Tropfen Benzin mit Kaffee; bald darnach verspürte el Aufstossen; el schwitzte etwas. Temperatur und Pulsfrequenz zeigten keinen erheblichen Unterschied. Den Tag ïber befand er sich sehr wohl; Appetit gut.

Am 24. September erhielt er 45 Tropfen Benzin, die er wiederum gut vertrug; am Nachnittage fühlte er sich besonders leicht in den Gliedern.

Am 1. Oktober erhielt er 60 Tropfen Benzin auf ein Mal, wonach er Aufstossen, Schwindel, Kopfweh verspürte.

Am 2. Oktober nahm er dagegen 40 Tropfen, ohne dass die genannten Erscheinungen ihn nachher belästigten.

Nach diesen Vorversuchen darf das Benzin auch beim Menschen innerlich angewandt werden, etwa in der Gabe von 10 Tropfen alle 3 Stunden, und verdient es, da wir bis jetzt kein wirksames Mittel gegen Trichiniasis kennen, besonders in dieser Krankheit versucht zu werden; um die dadurch getödteten Darmtrichinen rasch nach aussen zu schaffen, wird es geeignet sein, die Anwendung desselben mit der Darreichung von Abführmitteln zu verbinden, weun nicht durch die. Trichiniasis schon Diarrhöen herbeigefülıt sind. Weiterhin ist seine Wirkung zu erproben gegen Tä- 
nien und Askariden; gegen Oxyuren habe ich es bereits mit gutem Erfolg angewandt_in folgender Formel:

ly Benzini Ser. 1.

Vitelli Ovi Nr. 1.

Aq. dest. Unc. 4.

M. f. Emuls. DS. Zu 2 Klystieren.

Die nenerdings leider so massenhaft vorkommenden Trichinenerkrankungeu lassen uns den Mangel therapeutischer Versuche überall laut werden. Auf Anrathen befreundeter Collegen habe ich mich desshalb zur vorläufigen Mittheilung obiger Experimente entschlossen. Ich selbst würde alsbald zur weiteren Prüfung derselben geschritten seiı, wäre ich nicht durch eine längere wissenschaftliche Reise daran gehindert. Ich bin darum weit entfernt, in dieser Mittheilung das Benzin als Specitikum gegen die Trichinenkrankheit der Menschen anpreisen $z u$ wollen, da es sich ja vor Allem noch darum handelt, ob der fieberkranke Mensch das genannte Mittel in solcher Gabe vertragen wird, welche einen deletären Einfluss auf die Trichinen auszuüben verspricht. Ich würde es schon als einen grossen Gewinn ansehen, wenn es nur gelingen sollte, mit Benzin die Darmtrichinen zu tödten oder wenigstens ihre Zahl zu beschränken, und damit das massenhafte Einwandern von Embryonen zu verhindern.

Ich selbst hatte bis dahin keine Gelegenheit, die Trichinenkrankheit beim Menschen zu behandeln, glanbe aber, auf obige Resultate gestützt, diejenigen Collegen, welche ill diese Lage kommen, zu vorsichtigen Versuchen mit Benzin 
auffordern zu dïrfen, zumal wir kein anderes Mittel kennen, das bei Fütterungsversuchen Aehnliches geleistet, wie das Benzin. Icl habe vergleichsweise zahlreiche Medikamente in ihrer Wirkung auf Muskeltrichinen geprüft, wie es mit dem Natron picro-nitricum und einigen anderen Mitteln schon Fiedler bei seinen oben erwähnten, sehr gründlichen Versuchen gethan hat. Um die Lebensfähigkeit der Trichinen in den Lösungen oder Emulsionen verschiedener Arzneimittel zu constatiren, wird Muskelsubstanz mit lebenden Muskeltrichinen in dieselben ganz hineingelegt, und alsdann genall festgestellt, in welcher Zeit der Tod der Muskeltrichinen in den einzelnen Medikamenten erfolgt. Ich bin auf diesem Wege zu folgenden Resultaten gelangt:

1) Das reine Benzin und das 0l. animale Dippelii verhielten sich ganz gleich. Nachdem die genannte Muskelsubstanz darin 3-6 Stunden gelegen, waren sämmtliche Muskeltrichinen todt, bewegungslos, mit trübem körnigem lnhalte. Bei Trichinen, die schon eingekapselt, tritt eine deutliche Gerinnung des Inhaltes der Kapsel ein; die einzelnen Muskelbündel werden in dern Bezine gut isolirt, und lassen sich die dunkelen Trichinenkapseln leicht darin auffinden.

2) In Oleum Terebinthinae rectificatum wurden die Muskeltrichinen nach 30 Stunden noch lebend gefunden.

3) In reinem Chloroform waren die Trichinen nach 5 Stunden todt.

4) In Solutio arsenic. Fowler. waren die Muskeltrichinen nach 30 Stunden noch lebend.

5) In einer Mischung von Santonini Dr. $\frac{1}{2}$, Ol. Ricini, Ol. Olivarum ana Dr. 2 lebten die Muskeltrichinen noch nach 48 Stunden.

6) In einer Mischung von Extract. Filicis aeth. Dr. 1, 
Gummi arabici, Aq. dest. ana Une. $\frac{1}{2}$ lebten dieselben noch nach 30 Stunden.

7) Ein Gleiches ist von einem Decoct. Cort. Rad. Granatorum (c Dr. 2) Unc. $\frac{1}{2}$ zu berichten.

8) In einer Lösung von Jodkalium ( $\frac{1}{2}$ Dr. in 1 Une. Aq. (lest.) lebten die Mnskeltrichinen noch nach 30 Stnnden.

9) In einer Lösung von Chin. sulplı. (Gr. 8 gelöst in 1 Unc. Aq. dest.) lebten dic Mnskeltrichinen noch nach 20 Stunden.

10) In Liq. Kali carbon. Dr. 2, Aq. dest. Unc. 1 waren die Mnskeltrichinen nach 20 Stunden todt.

Aus dieser Tabelle gelat hervor, dass Benzin, Olemm animale Dippelii, und stark alkalische Lösungen am meisten zu Versuchen bei Trichinenkranken geeignet sind, zIImal diese Medikamente auf Darmtrichinen wahrscheinliclı noch viel rascher einwirken werden, als auf Muskeltrichinen.

Resumiren wir der Wichtigkeit des Gegenstandes wogen die von uns bezüglich der Wirkung des Benzins gemachten Erfahrungen, so sprechen dieselben jedenfalls dafïr, dass das Benzin ein stark wirkendes Medikament ist, das nach verschiedenen Richtungen weiler versucht zu werden verdient, zumal seine Wirkung und die Dosis, in welcher es vertragen werden kann, je nach der Verschiedenheit des Präparates sehr wechselt, wie die beiden von mir angewandten Präparate deutlich bewiesen haben. Von der stärkeren der beiden Sorten wurden vom Kaninchen 10 Gran, vom Schweine $\frac{1}{2}$ Drachme, vom Rinde $\frac{1}{2}$ Unce täglich läıgere Zeit hinter einander vertragen, ohne dass dentliche Intoxication bemerkt wurde. Von einem erwachsenen Manne wurden $30-40$ Tropfen pro dosi ohne besondere Beschwerden genommen. Nach 60 Tropfen pro dosi entstanden bei ihm nnangenehmes Aufstossen, Uebelkeit, 
Schwindel, Kopfschmer'z, Aufregung des Gefässssystemes, welche Symptome jedoch nur vorübergehend auftraten. Ich glaube hieraus schliessen zu dürfen, dass die Gabe, in welcher das Benzin vom erwachsenen Menschen vertragen wird, auf $1-2$ Drachmen im Tage angegeben werden darf; man wird etwa 2stündlich 10 Tropfen in capsules gelatin. nehmen lassen. Nach grösseren Gaben beobachtete ich bei Thieren sehr heftigen Schwindel, der sich bis zur Ohnmacht steigerte, Lähmungserscheinungen sowohl der sensibelen, wie der motorischen Nerven; sehr zu beachten ist ausserdem die Einwirkung der grossen Gaben von Benzin auf die Circulations- und Respirationsorgane, von welchen aus der exitus lethalis rasch zu erfolgen scheint.

Da nur sehr grosse Gaben diese ungünstigen Nebenwirkungen äusserten, dürfen uns dieselben nicht von ferneren Versuchen bezüglich der anthelminthischen Wirkung des Benzines beim Menschen in der von uns angedeuteten Weise abhalten. 
Gedruckt bei Julius Sittenfeld in Berlin. 


$$
0
$$





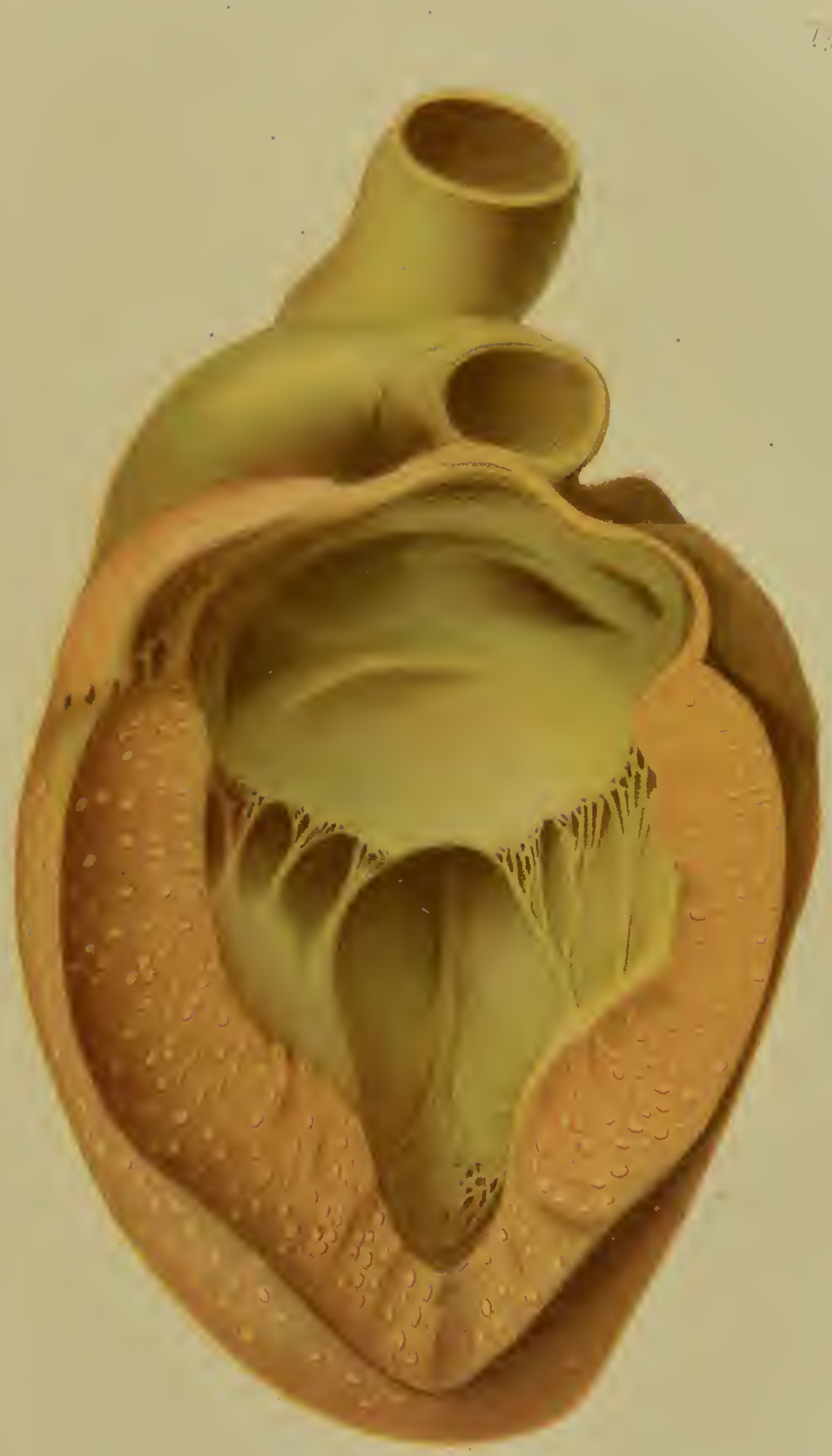



